\title{
Deletion of the Glutaredoxin-2 Gene Protects Mice from Diet-Induced Weight Gain, Which Correlates with Increased Mitochondrial Respiration and Proton Leaks in Skeletal Muscle
}

\author{
Adrian Young, Danielle Gardiner, Nidhi Kuksal, Robert Gill, Marisa O’Brien, and Ryan J. Mailloux
}

\begin{abstract}
Aims: The aim of this study was to determine whether deleting the gene encoding glutaredoxin-2 (GRX2) could protect mice from diet-induced weight gain.

Results: Subjecting wild-type littermates to a high fat diet (HFD) induced a significant increase in overall body mass, white adipose tissue hypertrophy, lipid droplet accumulation in hepatocytes, and higher circulating insulin and triglyceride levels. In contrast, GRX2 heterozygotes $\left(\mathrm{GRX}^{+/-}\right)$fed an HFD had a body mass, white adipose tissue weight, and hepatic and circulating lipid and insulin levels similar to littermates fed a control diet. Examination of the bioenergetics of muscle mitochondria revealed that this protective effect was associated with an increase in respiration and proton leaks. Muscle mitochondria from GRX2 $2^{+-}$mice had a $\sim 2$ - to 3 -fold increase in state 3 (phosphorylating) respiration when pyruvate/malate or succinate served as substrates and a $\sim 4$-fold increase when palmitoyl-carnitine was being oxidized. Proton leaks were $\sim 2$ - to 3-fold higher in $\mathrm{GRX}^{+/-}$muscle mitochondria. Treatment of mitochondria with either guanosine diphosphate, genipin, or octanoyl-carnitine revealed that the higher rate of $\mathrm{O}_{2}$ consumption under state 4 conditions was associated with increased leaks through uncoupling protein- 3 and adenine nucleotide translocase. GRX2 ${ }^{+/-}$mitochondria also had better protection from oxidative distress.

Innovation: For the first time, we demonstrate that deleting the Grx2 gene can protect from diet-induced weight gain and the development of obesity-related disorders.

Conclusions: Deleting the Grx2 gene protects mice from diet-induced weight gain. This effect was related to an increase in muscle fuel combustion, mitochondrial respiration, proton leaks, and reactive oxygen species handling. Antioxid. Redox Signal. 31, 1272-1288.
\end{abstract}

Keywords: glutaredoxin-2, reactive oxygen species, fuel metabolism, obesity, respiration, mitochondria

\section{Introduction}

$\mathbf{P}$ Rotein S-glutathionylation is a ubiquitous oxidative modification that involves the conjugation and removal of a glutathione molecule from cysteine (Fig. 1A) (43). Due to its unique physical and chemical features, mitochondria are highly susceptible to regulation by protein S-glutathionylation (14). These reactions are mediated by glutaredoxin-2 (GRX2), a thiol oxidoreductase that catalyzes the reversible S-glutathionylation of proteins in response to

\section{Innovation}

This study demonstrates for the first time that loss of glutaredoxin-2, a thiol oxidoreductase that mediates mitochondrial S-glutathionylation reactions, can prevent diet-induced obesity and related disorders. This is associated with a decrease in total S-glutathionylation adducts and increased fuel metabolism and proton leaks in muscle mitochondria.

Department of Biochemistry, Faculty of Science, Memorial University of Newfoundland, St. John's, Canada. 

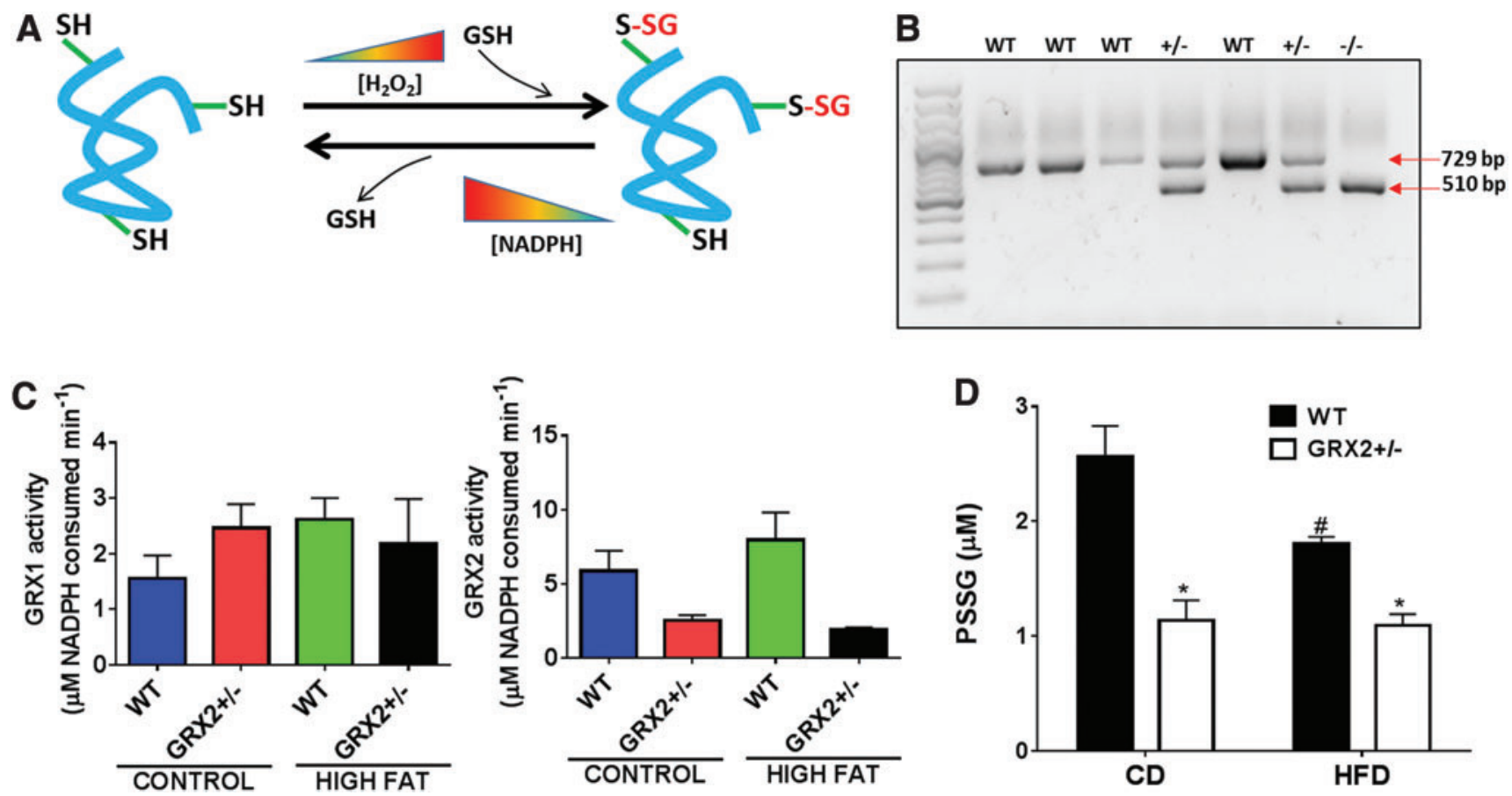

FIG. 1. Impact of deleting the Grx2 gene on GRX1 and GRX2 activity and overall amount of protein-glutathione mixed disulfides (PSSG). (A) A representative diagram for the modification of proteins with glutathione in response to alterations in cellular redox buffering capacity. (B) Genotypic characterization of mouse litters. RNA was extracted from ear notches and subjected to PCR analysis for the presence of the full-length or truncated forms of the Grx2 mRNA. (C) Assessment of GRX1 and 2 activity in mitochondrial fractions. Estimation of GRX activity in intermembrane space and the matrix was achieved by using the hydroxyethyldisulfide assay. (D) Estimation of the overall number of proteins modified by glutathione. PSSG adducts were measured by using a modified 5,5'-dithio-bis-[2-nitrobenzoic acid] assay. $n=3-4$, mean \pm SEM. Two-way ANOVA with a Fisher's LSD post hoc test. “*”" Denotes assessment of genotype effect. “\#” Denotes analysis of effect of diet within a genotype. ANOVA, analysis of variance; GRX2, glutaredoxin-2; LSD, least significance difference; SEM, standard error of the mean. Color images are available online.

fluctuations in the redox buffering capacity of the matrix. Changes in the redox state of the glutathione pool due to hydrogen peroxide $\left(\mathrm{H}_{2} \mathrm{O}_{2}\right)$ or NADPH availability dictates whether or not a protein will be deglutathionylated or S-glutathionylated by GRX2. For instance, complex I in heart mitochondria is deglutathionylated by GRX2 when the glutathione pool is highly reduced (e.g., when $\mathrm{H}_{2} \mathrm{O}_{2}$ is low) whereas it is $\mathrm{S}$-glutathionylated when glutathione disulfide is abundant (e.g., $\mathrm{H}_{2} \mathrm{O}_{2}$ levels are high) (29). Aside from complex I, mitochondria contain a number of proteins that are modulated by protein S-glutathionylation. This includes enzymes and proteins involved in mitochondrial fuel metabolism, oxidative phosphorylation and respiration, solute transport, mitochondrial fission/fusion, protein import, antioxidant defense, and apoptosis [reviewed in refs. $(24,50)]$. In addition, complex I has multiple S-glutathionylation sites, which have been postulated to fine tune its activity and rate of reactive oxygen species (ROS) release in response to different physiological cues and changes in mitochondrial redox state (27). It is important to acknowledge that glutathione $S$-transferases (GST) have also been shown to catalyze S-glutathionylation reactions in the cytoplasm and endoplasmic reticulum $(31,48)$. In addition, it is now apparent that GST plays a significant role in mediating these reactions in mammalian cells. However, it is unclear whether GST catalyzes the S-glutathionylation of proteins in the matrix of mitochondria.
Regular muscle physiology relies on redox signals to fine tune locomotion, facilitate adaptation to exercise, and regulate fuel metabolism (17). Skeletal muscle contains a number of cytosolic and mitochondrial proteins that are targeted for S-glutathionylation, which regulates myofiber contraction/ relaxation, energy metabolism, and ROS release from mitochondria $(10,17,38)$. Sarco/endoplasmic reticulum $\mathrm{Ca} 2+$ ATPase, $\mathrm{Na}+/ \mathrm{K}+$ ATPase, and ryanodine receptor-1, transporters that are critical for locomotion, are targets for regulation by protein S-glutathionylation (38). Contractile proteins, such as titin, troponin I, and troponin $\mathrm{C}$, are also sites for S-glutathionylation (38). There are also a number of sites for protein S-glutathionylation in muscle mitochondria. Recent work has found that mitochondrial pyruvate carrier is inhibited by protein S-glutathionylation (10). The same study also demonstrated that protein S-glutathionylation suppresses ROS release from muscle mitochondria (10). This effect was associated with the modification of complex I subunit, NDUFS1, as well as several other complex I subunits (10). Notably, conjugation of glutathione to NDUFS1 was previously found to inhibit complex I activity and diminish superoxide $\left(\mathrm{O}_{2}{ }^{--}\right) /$ $\mathrm{H}_{2} \mathrm{O}_{2}$ release in heart mitochondria by blocking access to the NADH binding site (15). Another important target for $\mathrm{S}$-glutathionylation in muscle mitochondria is uncoupling protein 3. It was found that the site-specific modification of $\mathrm{Cys}^{259}$ inhibits leaks through UCP3 whereas removing glutathione has the opposite effect (25). 
It was previously found that mice homozygous for the Grx2 gene displayed increased overall energy expenditure, an effect that correlated with the induction of UCP3dependent proton leaks (28). These effects were associated with a small but significant decrease in body and fat mass (28). Based on these findings, we hypothesized that manipulation of mitochondrial S-glutathionylation reactions by deleting the Grx2 gene would augment mitochondrial fuel metabolism in skeletal muscle, rendering mice resistant to diet-induced weight gain. Here, we report that partial deletion of the Grx2 gene completely protected mice from dietinduced weight gain and the development of obesity-related disorders. This effect was associated with increased mitochondrial fuel metabolism, proton leaks, ROS release, and redox buffering capacity. The implication of these findings in understanding the regulation of mitochondrial functions by redox signals and the impact it has on muscle physiology and metabolic disorders such as obesity are discussed herein.

\section{Results}

Partial removal of the Grx2 gene protects mice from diet-induced weight gain

It was previously demonstrated that mice homozygous for the Grx2 gene displayed a small but significant decrease in overall weight and adiposity at 9-12 weeks of age (28). However, a separate study also showed that mice homozygous for the Grx2 gene were predisposed to developing heart disease and hypertension as early as 6 weeks of age (29). Therefore, we opted to conduct our studies here using mice heterozygous for the Grx2 gene $\left(\mathrm{GRX} 2^{+/-}\right)$since they do not display any phenotypic changes in heart physiology (7). Immediately after weaning, mice were genotyped (Fig. 1B) and then wild-type (WT) and GRX2 $2^{+/-}$mice were placed on a high fat diet (HFD) or matched control diet (CD) and changes in weight were tracked until 9 weeks of age. There was no genotype or diet effect on the activity of GRX1 in intermembrane space fractions collected from muscle mitochondria, suggesting no compensatory change in response to the absence of GRX2 (Fig. 1C). Muscle mitoplast fractions collected from GRX2-deficient mice fed either diet displayed a $\sim 40 \%$ decrease in GRX2 activity (Fig. 1C). Next, we examined the impact of deleting the Grx2 gene on the overall number of protein-glutathione mixed disulfides (PSSG) in muscle mitochondria. Figure 1D demonstrates that muscle mitochondria from GRX2 $2^{+/-}$mice fed either diet contained significantly less PSSG adducts. Intriguingly, we also observed a diet effect in WT mice. Muscle mitochondria from WT mice fed an HFD displayed a significant decrease in the overall number of modified proteins when compared with WT mice fed a control-matched diet (Fig. 1D). In addition, no diet effect on the total number of PSSG adducts was observed in muscle mitochondria collected from $\mathrm{GRX}^{+/-}$mice.

Figure 2A demonstrates that WT mice fed an HFD displayed a significant increase in weight gain starting at 5 weeks of age. These mice continued to gain weight over time whereas the average mass of WT and GRX2 ${ }^{+/-}$mice fed a CD started to plateau by $\sim 5$ weeks of age (Fig. 2A). In contrast, $\mathrm{GRX}^{+/-}$mice fed an HFD displayed a weight gain profile that was identical to mice fed a CD (Fig. 2A). No significant changes in overall food consumption were observed over the 7 -week period, although there was a $14 \%$ and $8 \%$ increase, respectively, in WT and GRX2 $2^{+/-}$mice fed an HFD (Fig. 2B). Next, tissues and organs from WT and GRX2 $2^{+/-}$mice fed a $\mathrm{CD}$ or an HFD were collected and weighed. WT mice fed an HFD had significantly more abdominal fat (Fig. 2C). By contrast, GRX2-deficient mice fed an HFD had an abdominal fat mass that was similar to WT and GRX2 $2^{+/-}$mice fed a CD. We observed no diet or genotype effects on heart and kidney mass, respectively (Fig. 2C). However, liver mass was significantly lower in WT mice fed an HFD when compared with the control group and GRX2 $2^{+/-}$mice fed the same diet (Fig. 2C). Overall, muscle mass was also lower in WT mice fed an HFD whereas no differences were observed in GRX2 heterozygotes.

\section{GRX2 heterozygotes are resistant toward hepatic lipid and circulating triglyceride accumulation}

The development of obesity in C57BL/6N mice fed an HFD is accompanied by the rapid accumulation of lipids in hepatocytes, resulting in micro- and macrovacuolation (39, 40). Hematoxylin and eosin (H\&E) staining of liver sections revealed that WT mice fed an HFD displayed a high degree of vacuolation (Fig. 3A). In contrast, liver sections collected from GRX2 heterozygous mice subjected to an HFD contained less vacuoles and had a histological staining pattern similar to that observed in WT and GRX2 $2^{+/-}$mice fed a CD (Fig. 3A). Next, liver sections were stained with Oil Red-O reagent to examine overall hepatic lipid levels. WT mice fed an HFD displayed a significant accumulation of intrahepatic lipids, denoted by the presence of neutral lipid droplets stained in red (Fig. 3B). By contrast, the Oil Red-O staining pattern of liver samples collected from GRX2 $2^{+/-}$mice fed an HFD was similar to the controls (Fig. 3B).

It was found in Figure $2 \mathrm{C}$ that dissected livers from WT mice fed an HFD displayed a $\sim 10 \%$ decrease in overall mass. However, H\&E staining revealed no morphological changes in tissues collected from WT mice fed an HFD (Fig. 3A). Glycogen makes up $\sim 10 \%$ of the liver's total mass (47). Based on this information, we decided to subject liver sections to a periodic acid Schiff (PAS) stain. Figure 3C demonstrates that liver sections from WT and GRX2 ${ }^{+/-}$fed a CD displayed similar uniformity in terms of intrahepatic glycogen staining. GRX $2^{+/-}$mice fed an HFD also displayed a staining pattern that was similar to mice from either genotype fed a CD (Fig. 3C). However, staining liver sections from WT mice fed an HFD revealed that intrahepatic glycogen granules were depleted, which accounts, to a certain extent, for the decrease in liver mass (Fig. 3C).

Subjecting mice to CD or HFD feeding did not alter blood glucose levels over a course of 5 weeks (Fig. 4A). However, circulating triglycerides were almost $\sim 3$-fold higher in WT mice on an HFD (Fig. 4B). By contrast, GRX2 heterozygotes subjected to high fat feeding had triglyceride levels that were similar to both CD groups (Fig. 4B). Similar trends were also observed with circulating insulin levels. HFD feeding induced a significant increase in circulating insulin levels in WT mice (Fig. 4C). In addition, there was a significant increase in heterozygous mice fed a HFD when compared with $\mathrm{GRX}^{+/-}$control. However, insulin levels were still $\sim 3$-fold higher in WT mice fed an HFD (Fig. 4C). Taken together, these results indicate that the partial deletion of the Grx2 gene protects from diet-induced weight gain and hepatic lipid 

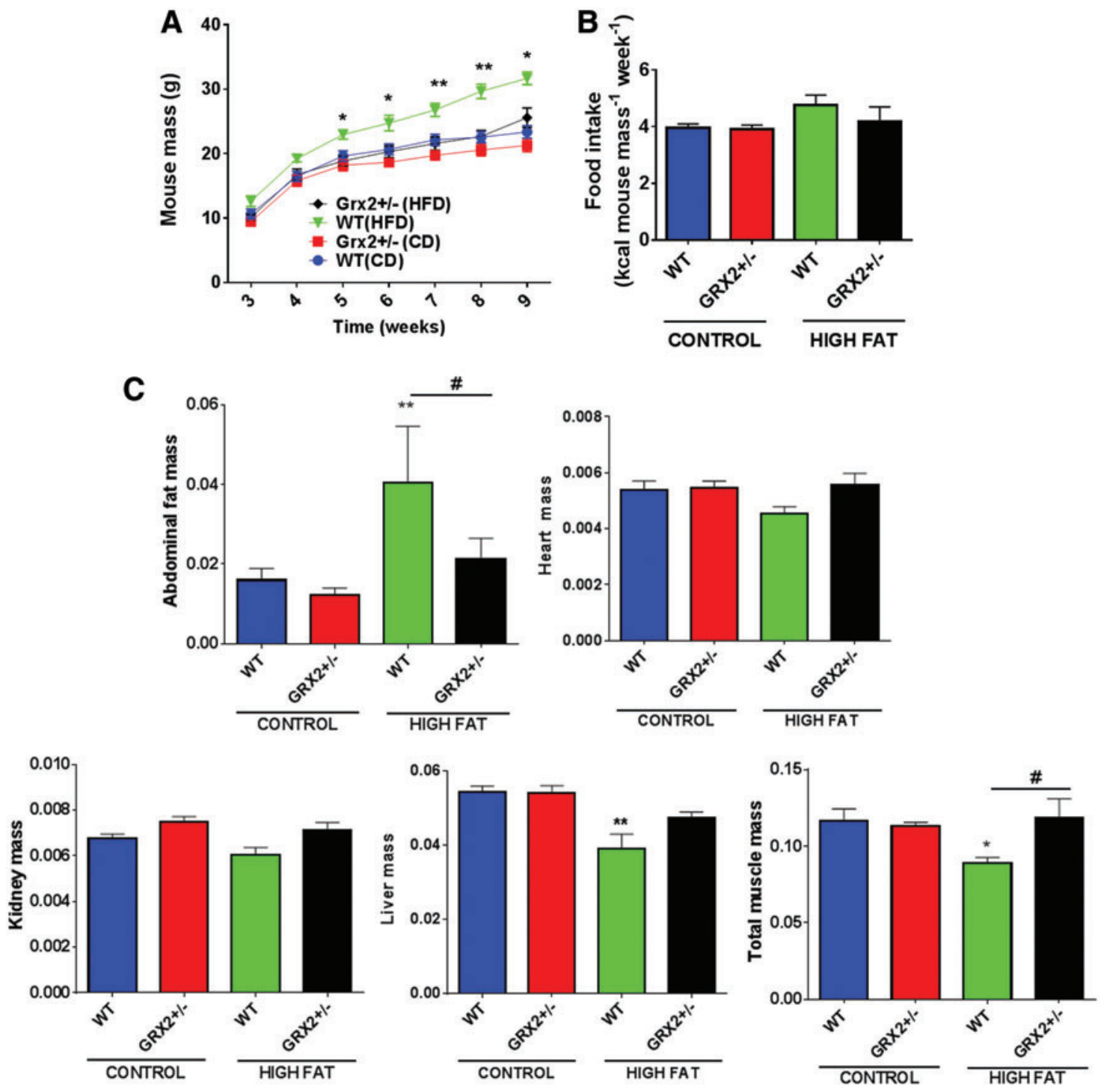

FIG. 2. Mice heterozygous for the $G r x 2$ gene are protected from diet-induced weight gain. (A) Mass of mice fed a $\mathrm{CD}$ or an HFD. $n=5-6$, mean \pm SEM. Two-way ANOVA with a Tukey's post hoc test. (B) Food consumption. $n=5-6$, mean \pm SEM. (C) Organ and tissue mass measurements. Total muscle $=$ mass of fore and hind limb and pectoral muscles combined. Mass was calculated as the ratio of the tissue mass to overall body mass in Figure 1B. $n=4-7$, mean \pm SEM. Two-way ANOVA with a Fisher's LSD post hoc test. “*” Denotes assessment of genotype effect. "\#” Denotes analysis of effect of diet within a genotype. $* * p \leq 0.01$. CD, control diet; HFD, high fat diet. Color images are available online.
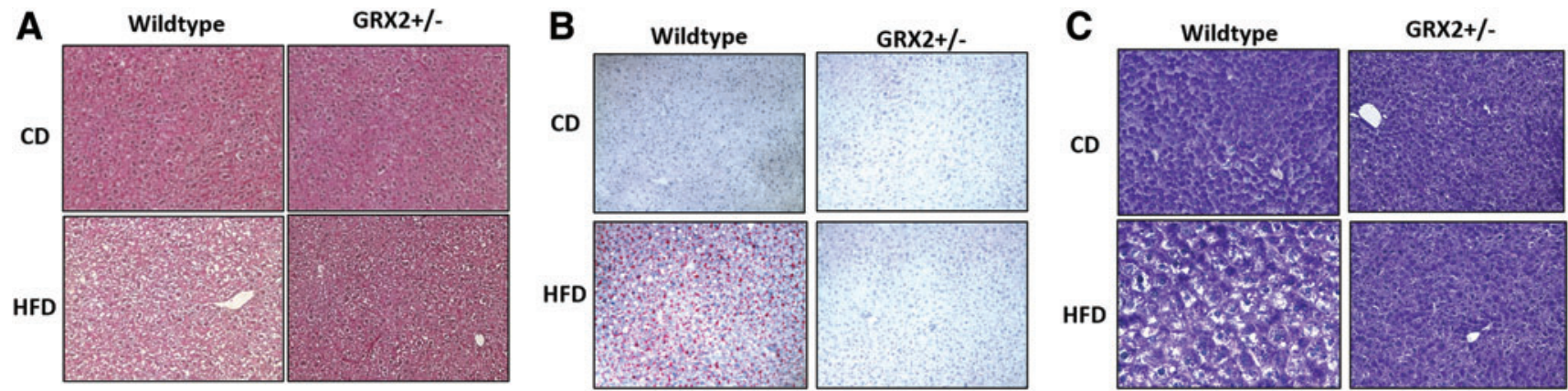

FIG. 3. Partial deletion of the Grx2 gene prevents hepatic lipid accumulation and depletes intrahepatic glycogen levels. (A) Hemotoxylin and eosin staining of liver sections prepared from 10-week-old GRX2 ${ }^{+-}$mice and WT littermates fed a CD or an HFD. $n=4$. (B) Oil Red-O staining of liver sections prepared from 10-week-old GRX2 ${ }^{+/}$mice and WT littermates fed a CD or an HFD. $n=4$. (C) Periodic acid Schiff staining of liver sections prepared from 10-week-old $\mathrm{GRX}^{+/-}$mice and WT littermates fed a CD or an HFD. $n=3$. WT, wild-type. Color images are available online. 

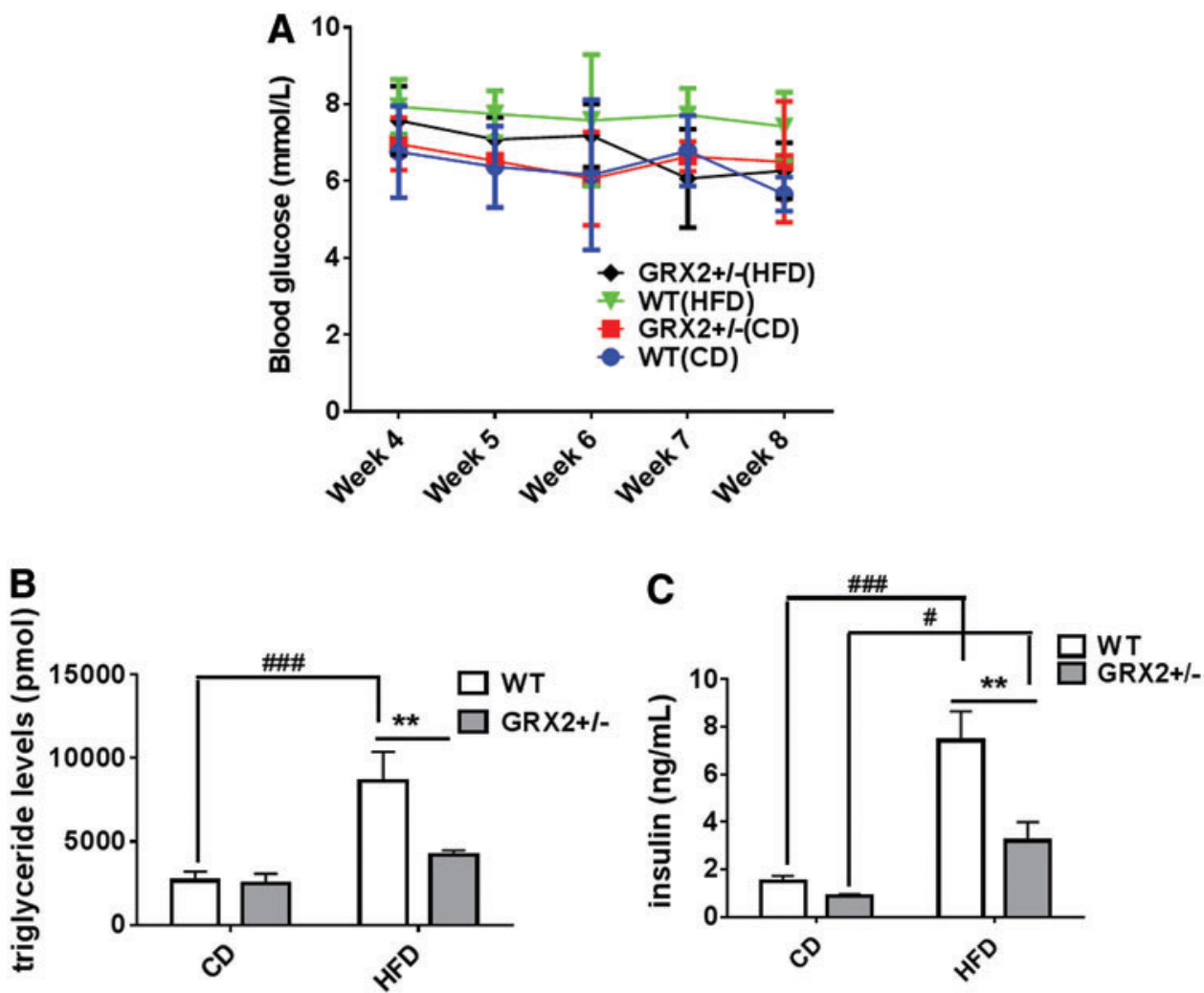

FIG. 4. Loss of the Grx2 gene increases circulating insulin and triglyceride levels. (A) Blood glucose levels. Glucose concentration was assessed weekly. $n=5-$ 7, mean \pm SEM. (B) Measurement of circulating triglyceride levels. Measurements were conducted using blood samples collected by cardiac puncture at 10 weeks of age. $n=5$, mean \pm SEM, one-way ANOVA with a Fisher's LSD post hoc test. (C) Measurement of circulating insulin levels. Measurements were conducted by using blood samples collected by cardiac puncture at 10 weeks of age. $n=5$, mean \pm SEM, one-way ANOVA with a Fisher's LSD test. "*" Denotes assessment of genotype effect. "\#” Denotes analysis of effect of diet within a genotype. ${ }^{* *} p \leq 0.01$, $\# \# \# p \leq 0.001$. Color images are available online. accumulation, an effect that is related to the maintenance of normal blood triglyceride and insulin levels. Our findings also indicate for the first time that deleting the Grx2 gene protects the liver from potential metabolic dysfunction through the provision of intrahepatic glycogen levels.

\section{Partial loss of GRX2 augments respiration and proton leaks in skeletal muscle mitochondria}

In a previous study, it was found that the deletion of the Grx2 gene induced a significant increase in state 3 respiration and proton leaks in muscle mitochondria (28). This effect correlated with increased overall energy expenditure and decreased body and fat mass (28). Therefore, we postulated that protection from diet-induced weight gain and related disorders in GRX2 $2^{+/-}$was due to increased mitochondrial fuel metabolism and proton leaks. H\&E staining of gastrocnemius muscle revealed that the partial deletion of the Grx2 gene did not alter the histology of the tissue (Fig. 5A). Muscle mitochondria isolated from WT mice fed an HFD displayed no changes in state 2, state 3 (phosphorylating), or state 4 (proton leaks) respiration relative to WT control when pyruvate and malate served as substrates (Fig. 5B). Intriguingly, mitochondria from $\mathrm{GRX}^{+/-}$muscle displayed a $\sim 2$-fold increase in phosphorylating respiration when pyruvate and malate were being oxidized, regardless of whether or not the mice were fed a CD or an HFD. Induction of state 4 respiratory conditions with oligomycin also revealed that proton leaks were significantly higher in $\mathrm{GRX}^{+/-}$mitochondria oxidizing pyruvate when compared with WT samples (Fig. 5B). Similar results were collected with mitochondria energized with succinate. GRX2 $2^{+/-}$mitochondria displayed a $\sim 2$-fold and $\sim 2$ - to 3-fold increase in state 3 and proton leaks-dependent respiration, respectively, during the oxidation of succinate, respectively, when compared with samples enriched from WT mice fed a CD or an HFD (Fig. 5C). We also tested whether the partial absence of GRX2 could augment the use of palmitoyl-carnitine as a fuel for mitochondrial respiration. Figure 5D demonstrates that phosphorylating respiration was $\sim 4$-fold higher in $\mathrm{GRX}^{+/-}$muscle mitochondria collected from mice fed a $\mathrm{CD}$ or an HFD when palmitoyl-carnitine served as the substrate. In addition, state 4 respiration was also $\sim 2$ - to 3 fold higher in GRX2 $2^{+/-}$mitochondria oxidizing palmitoylcarnitine (Fig. 5D).

The results collected above prompted us to assess the protein levels of various electron transport chain subunits to ascertain whether the increase in $\mathrm{O}_{2}$ consumption was related to changes in the availability of the respiratory complexes. Although some slight differences in the ATP5A subunit for complex $\mathrm{V}$ were observed, there were no apparent changes in the expression of complex I (NDUFB8), complex II (SDHB), complex III (UQCRC2), or complex IV (MTCO1) subunits (Fig. 6A and Supplementary Fig. S1). We also immunoblotted for pyruvate dehydrogenase (PDH) and alphaketoglutarate dehydrogenase (KGDH), critical ROS sources and entry points for fuel into the Krebs cycle. All three subunits corresponding to PDH displayed increased expression in muscle mitochondria enriched from $\mathrm{GRX}^{+/-}$mice fed a CD or an HFD (Fig. 6B and Supplementary Fig. S2). Increased expression of PDH was also observed in muscle mitochondria from WT mice fed a HFD (Fig. 6B and Supplementary Fig. S2). No alterations in the expression pattern of the E1 subunit of KGDH were observed in samples 
A

FIG. 5. Augmented fuel combustion, respiration, and proton leaks in muscle mitochondria from mice heterozygous for the Grx2 gene. (A) Hemotoxylin and eosin of gastrocnemius muscle prepared from 10week-old GRX2 ${ }^{+/-}$mice and WT littermates fed a CD or an HFD. $n=4$. (B) Assessment of the rate of $\mathrm{O}_{2}$ consumption in mitochondria subjected to different respiratory states. Mitochondria were energized with pyruvate and malate (10 and $2 \mathrm{mM}$, respectively), succinate $(10 \mathrm{~m} M)$ or palmitoyl-carnitine, and carnitine $(50 \mu M$ and $2 \mathrm{~m} M$, respectively) to induce state 2 respiration. State 3 and 4 respiration was measured after the addition of ADP $(1 \mathrm{~m} M)$ and oligomycin $(4 \mu \mathrm{g} / \mathrm{mL})$. $n=5$, mean \pm SEM, one-way ANOVA with a Fisher's LSD test. “*” Denotes assessment of genotype effect. $* p \leq 0.05$, ** $p \leq 0.01$, $* * * p \leq 0.001$, **** $p \leq 0.0001$. ADP, adenosine diphosphate. Color images are available online.
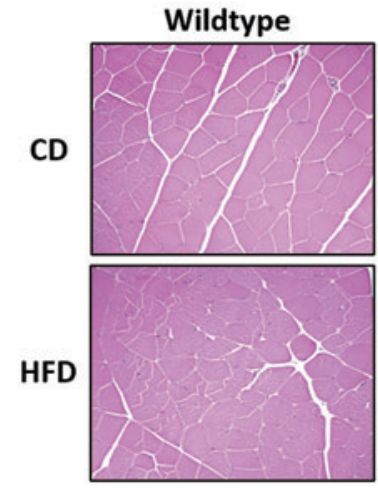

GRX2+/-
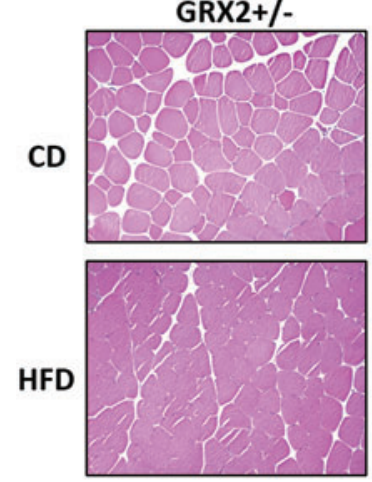

B
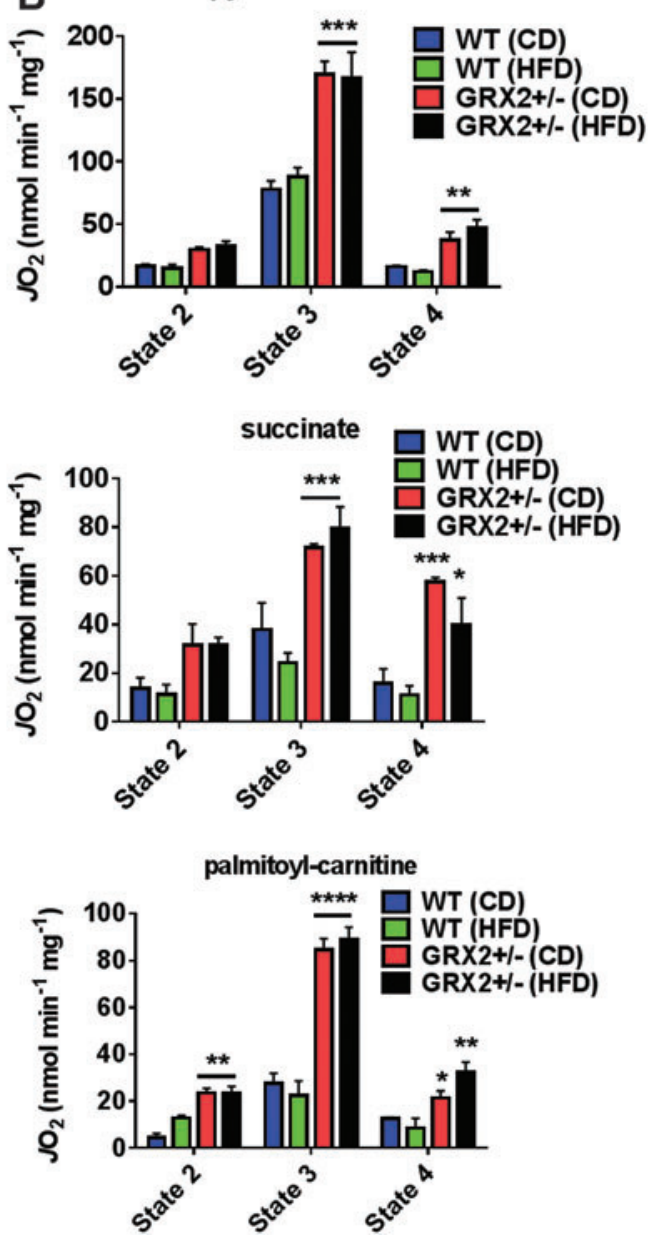

collected from WT and GRX2 ${ }^{+/-}$mice fed a CD or an HFD (Fig. 6C and Supplementary Fig. S3).

\section{The increase in mitochondrial fuel metabolism is related to the induction of leaks through UCP3 and ANT}

UCP3 is a member of the mitochondrial anion carrier superfamily that is theorized to augment mitochondrial fuel metabolism and fatty acid combustion through the passive return of protons to the matrix (5). In addition, deglutathionylation of UCP3 activates proton return whereas the GRX2mediated reglutathionylation of the protein has the opposite effect. Based on this, we tested whether (i) the increase in fuel metabolism was, in part, related to the induction of leaks through UCP3 and (ii) whether a chemical Sglutathionylation catalyst could reverse this effect. To test this, mitochondria were incubated in oligomycin and then the rate of $\mathrm{O}_{2}$ consumption associated with leaks was measured before and after exposure to guanosine diphosphate (GDP) and genipin, two specific inhibitors for the UCPs. GDP diminished proton-leak dependent respiration by $\sim 40 \%$ in $\mathrm{GRX}^{+/-}$muscle mitochondria isolated from mice fed either a CD or an HFD (Fig. 7A). Genipin had a similar effect, decreasing state 4 respiration by $\sim 50 \%$ and $\sim 40 \%$, respectively, in $\mathrm{GRX}^{+/-}$muscle mitochondria from mice fed a CD or an HFD (Fig. 7A). By contrast, GDP and genipin had no significant effect on proton leak-dependent respira- tion in muscle mitochondria enriched from WT mice fed a CD or an HFD (Fig. 7A). Immunoblot analysis revealed no change in UCP3 levels, indicating that the increase in proton leaks in $\mathrm{GRX}^{+/-}$mice mitochondria was not associated with changes in protein expression (Fig. 7B and Supplementary Fig. S4).

The results collected in Figure 7A revealed that genipin and GDP only induced $\sim 40 \%-50 \%$ inhibition of nonphosphorylating respiration in $\mathrm{GRX}^{+/-}$mitochondria energized with pyruvate and malate. This led us to test the contribution of adenine nucleotide translocase (ANT) toward nonphosphorylating respiration using octanoyl-carnitine. Acylcarnitines have been shown to induce $>90 \%$ inhibition of ANT at a concentration of $34 \mu M$ (3). Using $150 \mu M$ octanoylcarnitine, we found that ANT also made a significant contribution to nonphosphorylating respiration in muscle mitochondria isolated from GRX2 $2^{+/}$mice fed either diet (Fig. 7C). Indeed, octanoyl-carnitine induced a $\sim 34 \%$ and $\sim 25 \%$ decrease in respiration in mitochondria isolated from $\mathrm{GRX}^{+/-}$mice fed a CD and an HFD, respectively (Fig. 7C). By contrast, octanoyl-carnitine had no effect on ANT-mediated proton leaks in mitochondria from WT littermates fed either diet. After treating mitochondria with octanoyl-carnitine, GDP was injected into the measurement chamber to assess nonphosphorylating respiration associated with activated UCP3. Treatment with GDP lowered respiration by $\sim 84 \%$ and $\sim 71 \%$ in mitochondria isolated from $\mathrm{GRX}^{+/-}$mice fed a 

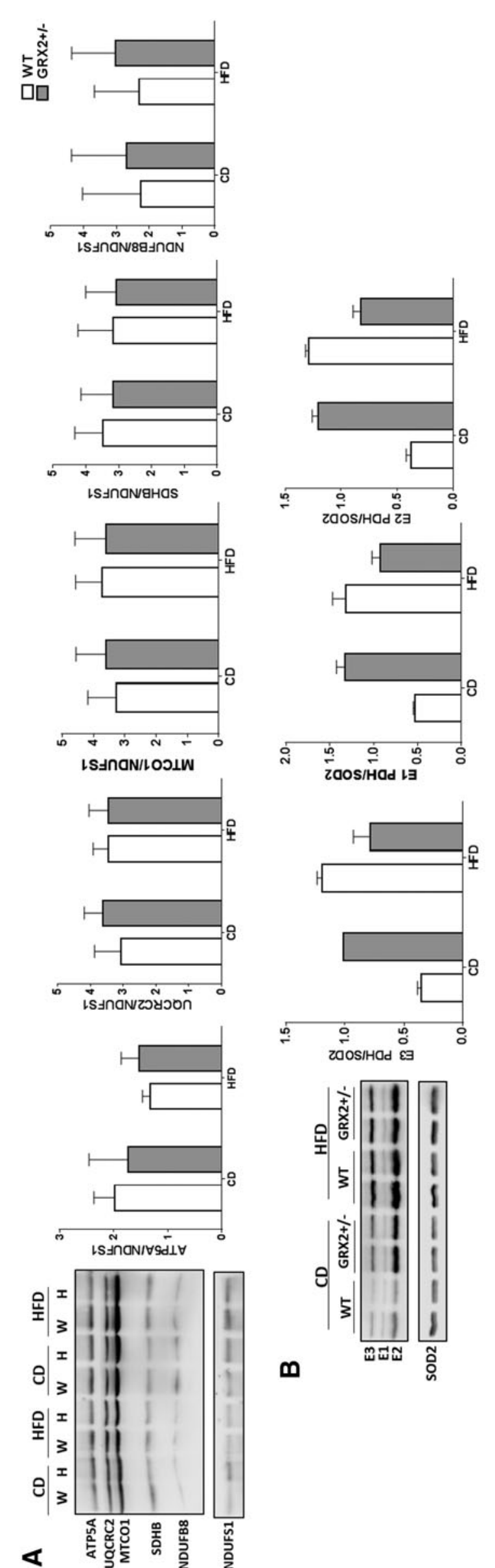

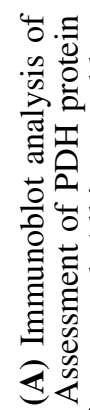
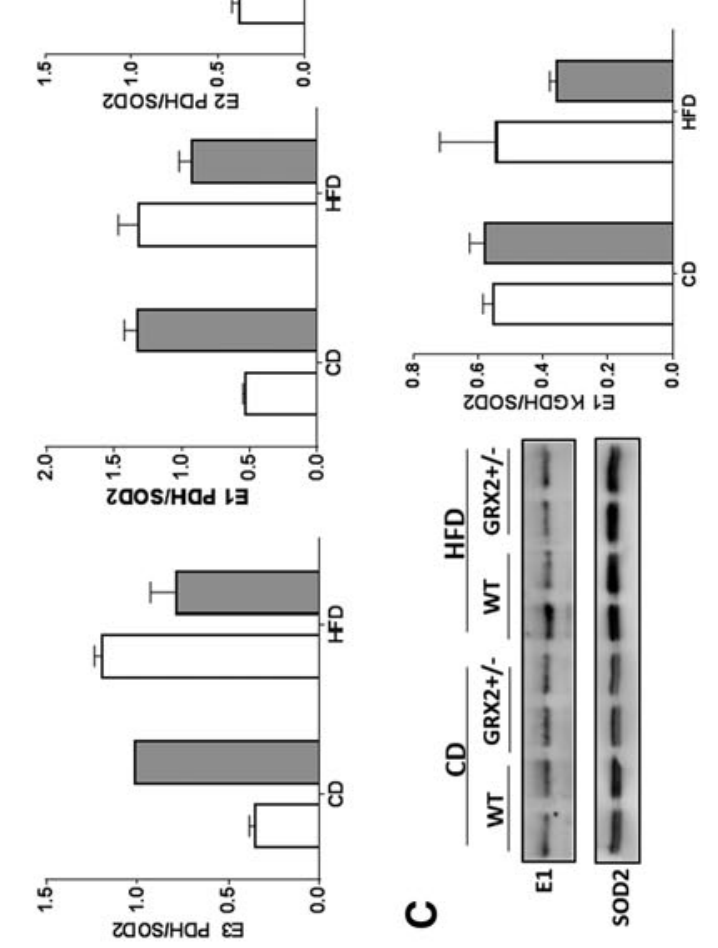

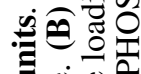
웜 क . ए 츤ํํํ 을 avi क्षे 든 흔

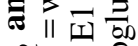
푼를 늘 을

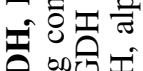

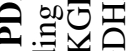
훙 范 웡

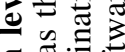
흐밍

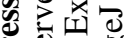
的哭 的

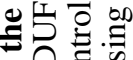
影 물 क力 흔

궁을

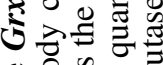
원

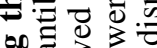

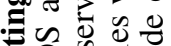

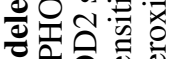
힝용

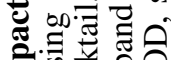
Iझ 웡 च 巳

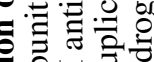
的表完

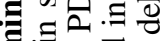

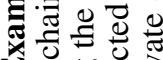
도 . 응 気 $\dot{0} \frac{0}{0} 0$

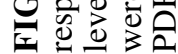



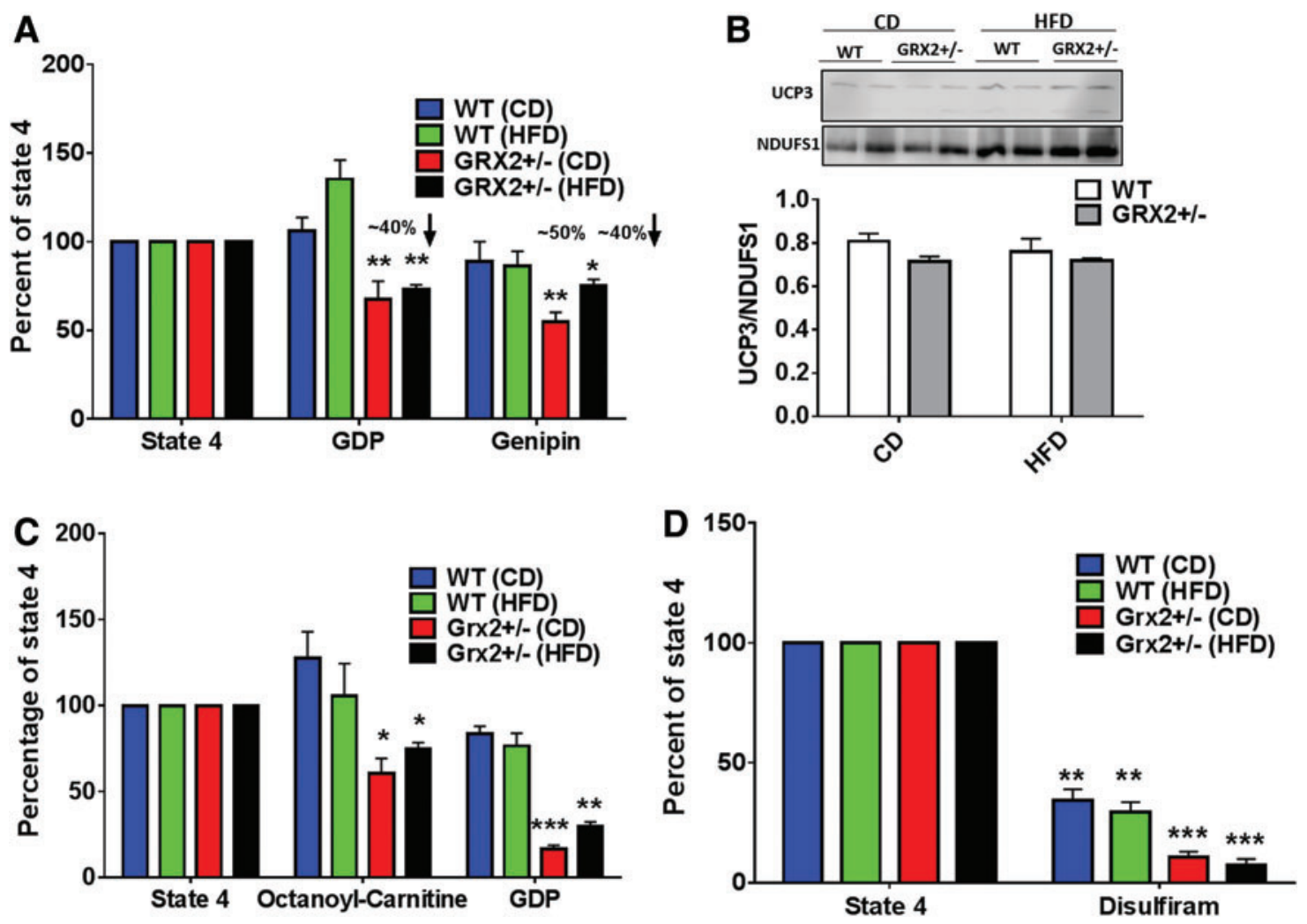

FIG. 7. Muscle mitochondria from mice heterozygous for the Grx2 gene have increased UCP3 and ANT-dependent nonphosphorylating respiration. (A) Nonphosphorylating respiration associated with proton return through UCP3 was examined by first treating muscle mitochondria with oligomycin $(4 \mu \mathrm{g} / \mathrm{mL})$. Mitochondria were energized with pyruvate and malate $(10$ and $2 \mathrm{mM})$ and then treated with either GDP $(1 \mu M)$ or genipin $(100 \mu M)$. Results were expressed as a percent of state 4 respiration to assess the impact of each individual inhibitor on overall proton leak-dependent $\mathrm{O}_{2}$ consumption. $n=5$, mean \pm SEM, one-way ANOVA with a Fisher's LSD post hoc test. The arrows signify the percentage decrease in respiration. (B) Immunoblot analysis of UCP3 levels. NDUFS1 served as the loading control. Bands were quantified by using ImageJ software. (C) Nonphosphorylating respiration related to ANT and UCP3 was first examined by inducing state 4 respiration using oligomycin $(4 \mu \mathrm{g} / \mathrm{mL})$ and pyruvate and malate $(10$ and $2 \mathrm{~m} M)$. ANT and UCP3 activity was then inhibited by using octanoyl-carnitine $(150 \mu M)$ and GDP $(500 \mu M) . n=4$, mean \pm SEM, one-way ANOVA with a Fisher's LSD post hoc test. (D) The impact of S-glutathionylation on state 4 respiratory capacity was examined by first treating mitochondria with oligomycin $(4 \mu \mathrm{g} / \mathrm{mL})$ and pyruvate and malate $(10$ and $2 \mathrm{~m} M)$ and then inducing the S-glutathionylation of proteins by using disulfiram $(500 \mu M) . n=4$, mean \pm SEM, one-way ANOVA with a Fisher's LSD post hoc test. "*" Denotes assessment of genotype effect. $* * p \leq 0.05, * * * p \leq 0.001$. ANT, adenine nucleotide translocase; GDP, guanosine diphosphate; $\mathrm{UCP}$, uncoupling protein. Color images are available online.

CD and an HFD diet, respectively (Fig. 7C). GDP also inhibited respiration by WT mitochondria but only by $\sim 31 \%$ and $35 \%$ in samples isolated from mice fed a CD and an HFD (Fig. 7C). Next, we tested the impact of the chemical S-glutathionylation catalyst, disulfiram, on proton leaks. Disulfiram decreased nonphosphorylating respiration in all samples, which is not surprising considering that it is a nonspecific S-glutathionylation agent that likely modifies a number of proteins involved in respiration (Fig. 7D). Notably, however, disulfiram almost completely abolished nonphosphorylating respiration in $\mathrm{GRX}^{+/-}$mitochondria collected from mice fed a CD or an HFD. This is in comparison to WT mitochondria, where it was decreased by $\sim 65 \%$ (Fig. 7D). It is likely that this effect in $\mathrm{GRX}^{+/-}$is related to the modification of several proteins outside of UCP3 and ANT. However, the impact on proton leaks also cannot be discounted. Taken together, partial loss of GRX2 augments nonphosphorylating respiration through the in- duction leaks through UCP3 and ANT in muscle mitochondria.

\section{$\mathrm{GRX}^{+/-}$mitochondria produce more ROS}

Increased mitochondrial fuel metabolism in muscle can augment ROS production. It has also been documented that increased leaks through UCP3 and fuel metabolism in muscle mitochondria isolated from mice homozygous for GRX2 also have increased rates of ROS release (28). Similar observations have been made after the activation of UCP1 in brown fat $(9,32)$. Therefore, we measured the rate of $\mathrm{H}_{2} \mathrm{O}_{2}$ production by GRX2 $2^{+/-}$and WT mice fed a CD or an HFD. $\mathrm{GRX}^{+/-}$mitochondria collected from mice fed a CD or an HFD produced significantly more $\mathrm{H}_{2} \mathrm{O}_{2}$ than WT samples when pyruvate was being oxidized (Fig. 8A). Similar observations were made with succinate. Oxidation of succinate induced a higher rate of $\mathrm{H}_{2} \mathrm{O}_{2}$ production in $\mathrm{GRX} 2^{+/-}$ 

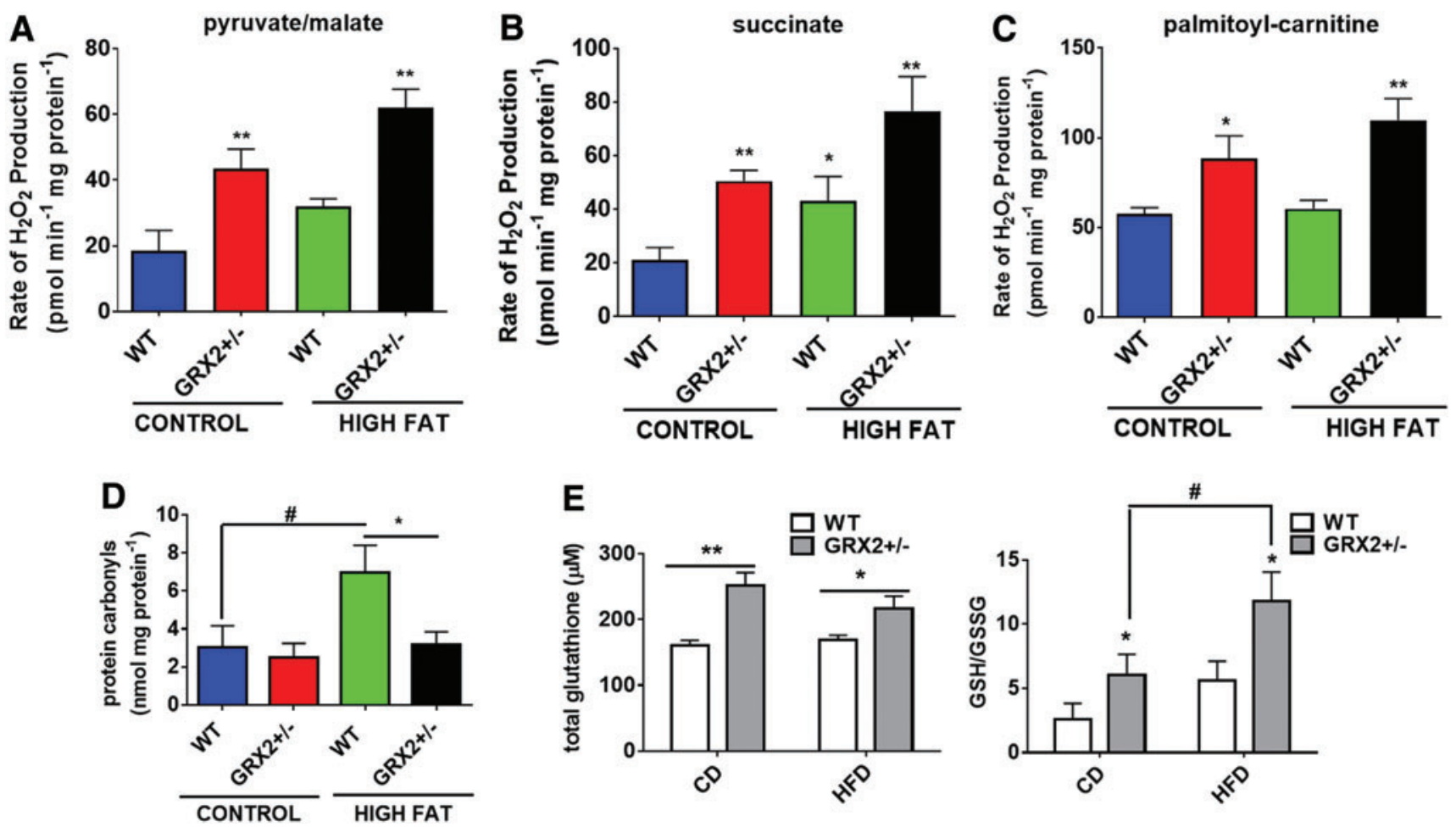

FIG. 8. Muscle mitochondria from mice heterozygous for the Grx2 gene display higher rates for $\mathrm{H}_{2} \mathrm{O}_{2}$ production but also have increased ROS-handling capacity. (A-C) The rate of $\mathrm{H}_{2} \mathrm{O}_{2}$ production by mitochondria energized with pyruvate and malate (A), succinate (B), and palmitoyl-carnitine and carnitine (C) was estimated by using the Amplex UltraRed assay. For experiments with pyruvate and malate or succinate, mitochondria were supplemented with $50 \mu M$ substrate. For palmitoyl-carnitine, mitochondria were preloaded with carnitine $(2 \mathrm{~m} M)$ and then supplemented with $20 \mu M$ palmitoyl-carnitine. $n=4-5$, mean \pm SEM, one-way ANOVA with a Fisher's LSD post hoc test. (D) Measurement of protein oxidation adducts in skeletal muscle mitochondria. $n=4$, mean \pm SEM, one-way ANOVA with a Fisher's LSD post hoc test. (E) Quantification of circulating glutathione levels and calculation of the GSH/GSSG ratio. $n=4-6$, mean \pm SEM, two-way ANOVA with a Fisher's LSD post hoc test. "*” Denotes assessment of genotype effect. "\#” Denotes analysis of effect of diet within a genotype. ${ }^{*} p \leq 0.01$. GSH, reduced glutathione; GSSG, glutathione disulfide; $\mathrm{H}_{2} \mathrm{O}_{2}$, hydrogen peroxide; ROS, reactive oxygen species. Color images are available online.

mitochondria (Fig. 8B). However, muscle mitochondria isolated from WT littermates fed an HFD also displayed higher rates of release when succinate served as the substrate. Finally, the rate of $\mathrm{H}_{2} \mathrm{O}_{2}$ release from $\mathrm{GRX}^{+/-}$mitochondria was also significantly higher when palmitoyl-carnitine was being oxidized (Fig. 8C).

Mitochondrial $\mathrm{H}_{2} \mathrm{O}_{2}$ production is integral for normal muscle physiology and plays a vital role for adaptation to exercise. These adaptations also include augmenting redox buffering capacity and increasing resistance toward oxidative distress. This allows muscle to use ROS for cell signaling while avoiding its deleterious effects. We thus decided to test protein carbonyl levels in muscle mitochondria, a biomarker for oxidative distress. Figure 8D shows that, unlike WT mice fed an HFD, which contained significantly higher amounts of protein carbonyls, GRX2 $2^{+/-}$muscle mitochondria from $\mathrm{CD}$ or HFD mice contained protein carbonyl levels that were similar to WT control. Analysis of plasma samples revealed that $\mathrm{GRX}^{+/-}$mice contained more glutathione, suggesting that heterozygous mice have a higher redox buffering capacity (Fig. 8E). Further, the glutathione pool was more reducing in plasma samples collected from GRX2 $2^{+/-}$mice fed an HFD. Together, these results demonstrate that manipulating mito- chondrial redox signals by deleting the Grx2 gene can augment ROS production for adaptive signaling (e.g., enhancing antioxidant capacity).

\section{Analysis of the high-capacity sites for ROS production}

Muscle mitochondria can contain up to 12 sites for $\mathrm{H}_{2} \mathrm{O}_{2}$ production (4). In addition, $\mathrm{H}_{2} \mathrm{O}_{2}$ is also produced by the same fuel combusting and electron transferring pathways in mitochondria that support respiration and ATP generation. Based on the relationship between high fuel metabolism, mitochondrial bioenergetics, and $\mathrm{H}_{2} \mathrm{O}_{2}$ genesis, we decided to determine which ROS-producing enzymes serve as highcapacity sites of production in WT and GRX2 $2^{+/-}$mitochondria. We decided to focus on ascertaining how much ROS was released from $\mathrm{KGDH}$ and complexes I, II, and III since all four enzymes were previously characterized as highcapacity sites for production in muscle, liver, and heart mitochondria (4). Surprisingly, the $\mathrm{KGDH}$ inhibitor 3methyl-2-oxovaleric acid (KMV) did not induce any significant changes in ROS production, suggesting that it is not a source of $\mathrm{H}_{2} \mathrm{O}_{2}$ when pyruvate/malate served as substrates (Fig. 9A). Myxothiazol, an ROS production inhibitor for 
A
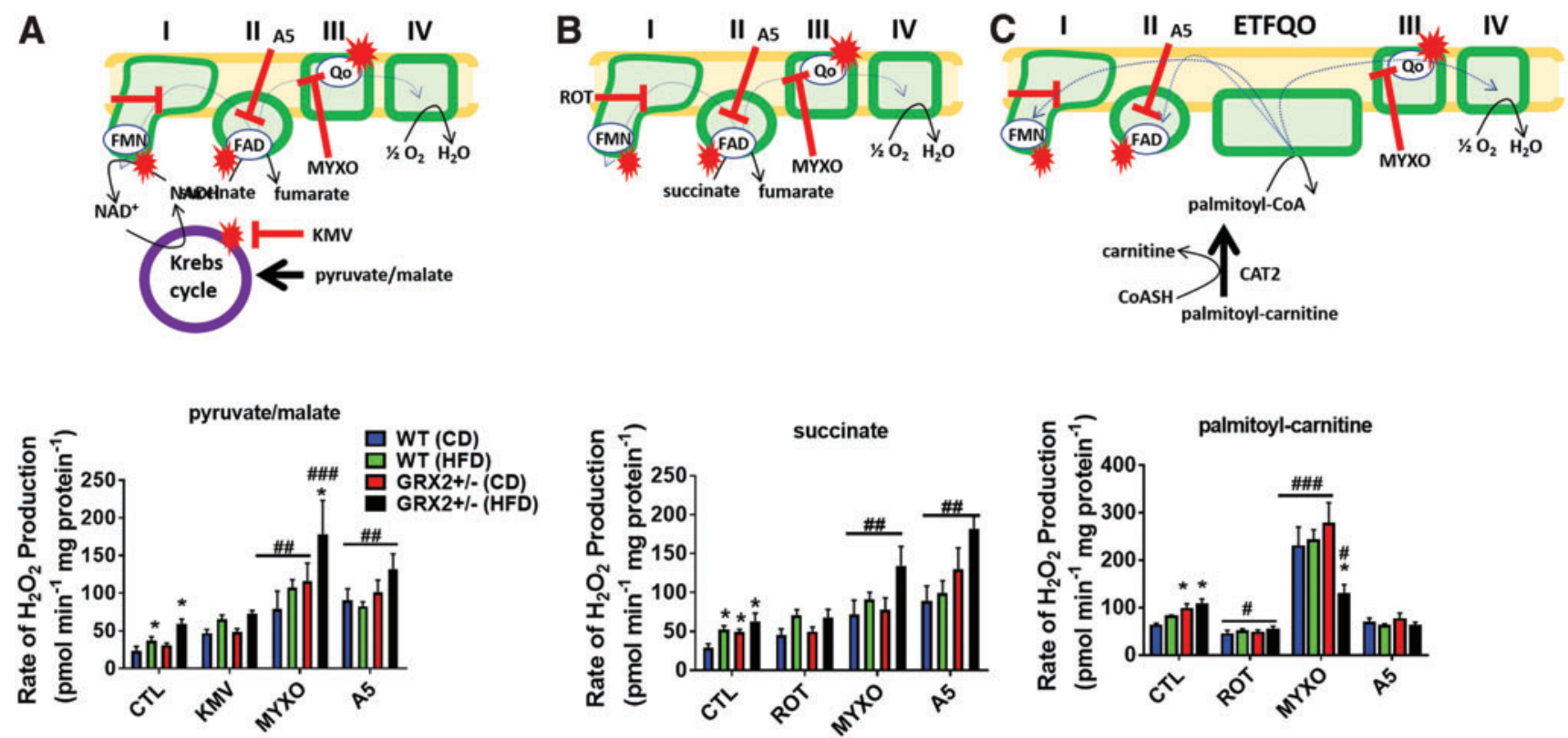

FIG. 9. Complexes I and II serve as the major sources of ROS in muscle mitochondria. (A) Sources of $\mathrm{H}_{2} \mathrm{O}_{2}$ production in mitochondria energized with pyruvate $(50 \mu M)$ and malate $(50 \mu M)$ were interrogated by using the following site-specific inhibitors: 3-methyl-2-oxovaleric acid (KMV; KGDH inhibitor), atpenin A5 (A5; complex II inhibitor), and myxothiazol (Myxo; complex III inhibitor. (B) Sources of $\mathrm{H}_{2} \mathrm{O}_{2}$ production in mitochondria energized with succinate $(50 \mu M)$ were interrogated by using the following site-specific inhibitors: rotenone (Rot; complex I inhibitor, atpenin A5 [A5; complex II inhibitor]) and myxothiazol (Myxo; complex III inhibitor). (C) Sources of $\mathrm{H}_{2} \mathrm{O}_{2}$ production in mitochondria energized with palmitoyl-carnitine $(20 \mu M)$ and carnitine $(2 \mathrm{mM})$ were interrogated by using the following sitespecific inhibitors: rotenone (Rot; complex I inhibitor, atpenin A5 [A5; complex II inhibitor]) and myxothiazol (Myxo; complex III inhibitor). Sites of action for the different ROS production inhibitors are indicated by red arrows. Red stars indicate the ROS source, and dotted arrows denote the direction of electron flow in the respiratory chain. For all experiments, $\mathrm{O}_{2}{ }^{--} / \mathrm{H}_{2} \mathrm{O}_{2}$ production was measured by using Amplex UltraRed under state 4 respiratory conditions. $n=5-7$, mean \pm SEM, two-way ANOVA with a Fisher's LSD post hoc test. "**” Denotes a comparison to WT on CD diet within an inhibitor treatment group. "\#” Denotes a comparison of inhibitor treatment with control group (no inhibitors added). $\# \# p \leq 0.01$, \#\#\#p $\leq 0.001$. KGDH, alpha-ketoglutarate dehydrogenase; KMV, 3-methyl-2-oxovaleric acid. Color images are available online.

complex III, and atpenin A5, which blocks reverse electron flow from the ubiquinone pool to the ROS-producing flavin adenine dinucleotide (FAD) center in complex II, induced significant increases in ROS release (Fig. 9A). This would suggest that when pyruvate is serving as the oxidizable substrate, complex I is the chief site of production. Next, we conducted similar experiments using succinate as the sole substrate. Surprisingly, rotenone did not block ROS release in WT or GRX2 $2^{+-}$mitochondria, indicating that reverse electron flow to complex I is not a source of $\mathrm{H}_{2} \mathrm{O}_{2}$ when succinate is the substrate (Fig. 9B). Myxothiazol augmented the rate of $\mathrm{H}_{2} \mathrm{O}_{2}$ production and atpenin A5 had a similar effect (Fig. 9B). Atpenin A5 blocks electron transfer from the ROSgenerating FAD center to the ubiquinone-binding pocket in complex II. Therefore, complex II is the major ROS source when succinate is being metabolized. Finally, we tested which sites generate ROS when palmitoyl-carnitine serves as the substrate. It was found that rotenone induced a $\sim 50 \%$ decrease in ROS release whereas myxothiazol had the opposite effect, increasing production by mitochondria isolated from WT and GRX2 $2^{+/}$mice (Fig. 9C). Atpenin A5 induced a $\sim 20 \%$ decrease in production but the effect was not significant when compared with mitochondria not treated with inhibitors. Therefore, the high-capacity sites for production when palmitoyl-carnitine served as the substrate were complex I and, to a lesser extent, complex II. Overall, these results suggest that muscle mitochondria isolated from C57B16N mice produce most of their ROS from complexes I and II.

\section{Discussion}

For the first time, we show that deleting the Grx2 gene, which is required to drive the reversible S-glutathionylation of proteins in mitochondria, can protect from diet-induced weight gain and intrahepatic lipid accumulation in response to high fat feeding. We found that this effect correlated with the augmentation of oxidative phosphorylation and proton leaks in muscle mitochondria, indicating that the dietinduced obesity (DIO) resistance phenotype observed in $\mathrm{GRX}^{+/-}$mice is associated with increased muscle fuel metabolism and fat combustion. To our knowledge, this is the first study to demonstrate that manipulation of mitochondrial redox signaling pathways by deleting the Grx2 gene can profoundly influence whole-body energy metabolism.

Protein S-glutathionylation reactions modulate mitochondrial bioenergetics, fuel selection and combustion, oxidative phosphorylation, and many other functions in various tissue and cell types [reviewed extensively in refs. (14, 24, 
$27,34,49,50)]$. In most cases, oxidation of mitochondrial glutathione pools results in the S-glutathionylation and inhibition of proteins involved in fuel combustion and oxidative phosphorylation. This occurs in response to the induction of oxidative eustress, which is required to protect mitochondrial proteins from oxidative damage while simultaneously limiting ROS production by inhibiting fuel combustion and electron transfer reactions through the respiratory complexes. Restoration of the reducing capacity of the glutathione pool has the opposite effect, resulting in the deglutathionylation of mitochondrial proteins and the restoration of fuel combustion and bioenergetics. Several studies have found that the reversible modification of mitochondrial proteins in response to alterations in the redox state of the matrix glutathione pool is mediated by GRX2 $(2,7,35,46)$. Oxidation of glutathione pools drives the GRX2-mediated modification of mitochondrial proteins whereas restoration of reduced glutathione (GSH) levels stimulates its deglutathionylase activity. Protein S-glutathionylation reactions also modulate the bioenergetics of muscle mitochondria through the reversible modification of several proteins, including complex I, solute anion carriers, and UCP3 $(10,26)$. Mice homozygous for the Grx2 gene have increased UCP3-dependent mitochondrial proton leaks and display an increase in respiration, which correlates with a small but significant decrease in body and fat mass (28). Therefore, S-glutathionylation reactions mediated through GRX2 are integral for regulating the bioenergetics of muscle mitochondria, which has an influence on whole-body energy metabolism.

There is a strong relationship between the induction of leaks and the prevention or reversal of obesity. For instance, the chemical uncoupler 2,4-dinitrophenol (DNP) was used to induce weight loss in the 1930s (11). However, due to its limited therapeutic window, use of DNP to induce weight loss was banned. After their identification, the UCPs became the new target for potential prevention and reversal of obesity by stimulating proton leaks. Overexpression of UCP3 by $\sim 2-$ fold increases fatty acid oxidation and energy expenditure (1). Exercise increases fat oxidation and UCP3 protein expression and overexpression of UCP3 in mice has an "exercise-like effect," protecting from obesity $(1,12)$. As noted earlier, deleting the Grx2 gene had been previously shown to increase leaks through UCP3, which correlates with increased mitochondrial respiration and an overall decrease in mouse mass. However, whether or not this can protect mice from diet-induced obesity has never been examined. To ascertain whether there was a relationship between deleting the Grx2 gene and the potential role of proton leaks in protecting mice from DIO, we challenged mice heterozygous for the Grx2 gene with an HFD. To our surprise, GRX2 $2^{++-}$mice were completely protected from diet-induced weight gain, dyslipidemia, and fat accumulation in hepatocytes when fed an HFD for several weeks. This is in contrast to WT littermates, which displayed an immediate increase in weight gain after exposure to an HFD, culminating with hepatic fat accumulation, white fat hypertrophy, and increased circulating triglycerides and insulin. The positive effects associated with the partial deletion of the Grx2 gene were associated with an increase in proton leaks through UCP3 and ANT in muscle mitochondria. These findings are consistent with two previously published studies demonstrating that UCP3 is a target for S-glutathionylation and $\operatorname{GRX} 2(25,28)$. It has been documented that glutathione can be conjugated to Cys ${ }^{25}$ and $\mathrm{Cys}^{259}$ in UCP3, which inhibits its activity and diminishes respiration (25). Similar results have been collected with UCP2 (22). In addition, GRX2 is required to deactivate proton return through UCP3 through its S-glutathionylation (18). Elimination of GRX2 induces the chronic activation of leaks in muscle mitochondria and primary mouse myotubes, which could be inhibited by S-glutathionylation catalysts or further activated by deglutathionylation agents such as dithiothreitol (DTT) (28). Moreover, in a study recently published by our group, we showed that disulfiram, a chemical catalyst for Sglutathionylation, can shut down leaks in muscle mitochondria (10). We generated similar results in this study where inclusion of disulfiram almost abolished nonphosphorylating respiration. It should be noted that disulfiram also disabled nonphosphorylating respiration in muscle mitochondria enriched from WT mice fed either diet. However, the disulfiram effect was much larger in samples collected from $\mathrm{GRX}^{+/-}$mice, indicating that loss of Grx2 results in the induction of leaks, potentially through the deglutathionylation of UCP3. We also show here for the first time that GRX2 may also target ANT for regulation by S-glutathionylation. Indeed, deleting the Grx2 gene resulted in an increase in leaks through ANT, as indicated by the augmented sensitivity of ANT toward inhibition by octanoyl-carnitine. ANT is also a known S-glutathionylation target but to our knowledge this is the first study to demonstrate that S-glutathionylation may serve as a regulator of inducible leaks through ANT (41). Collectively, these findings indicate that increasing leaks and fuel combustion through manipulation of matrix redox signaling could serve as a means for treating or preventing weight gain, but establishing this concept requires further investigation.

Metabolic gridlock caused by mitochondrial dysfunction is associated with inefficient fuel combustion and acylcarnitine accumulation, which is related to the development of metabolic diseases (33). Muscle mitochondria from GRX2 heterozygous mice displayed a $\sim 2$ - to 3-fold increase in phosphorylating respiration. Moreover, these mitochondria also had an enhanced capacity to combust palmitoyl-carnitine to support oxidative phosphorylation. Thus, the increased capacity to use acyl moieties as a fuel for respiration likely makes a major contribution toward the maintenance of body fat levels after high fat feeding. It is also important to consider the relationship between S-glutathionylation and bioenergetics and how manipulation of GRX2 can augment respiration and fat combustion. Targets for protein S-glutathionylation in muscle mitochondria include several Krebs cycle enzymes and respiratory complexes, such as complex I. Other important targets linked to fuel combustion include pyruvate carrier protein and the UCPs (10). In muscle, S-glutathionylation of complex I inhibits its activity through the modification of NDUFS1, a subunit required for the oxidation of NADH. Deglutathionylation of these targets is associated with increased state 3 respiration in mitochondria oxidizing complex I-linked substrates, pyruvate and malate, and the depletion of several Krebs cycle intermediates $(10,28)$. In this study, it was found that the deletion of the Grx 2 gene led to an overall decrease in the number of PSSG adducts, indicating that mitochondria are maintained in a more deglutathionylated state. Therefore, the increase in fuel combustion and respiration is related to alterations in the S-glutathionylation status of several mitochondrial proteins involved in nutrient uptake 
and oxidation. In addition, since proton leaks are higher, more fuels would need to be combusted to maintain the mitochondrial membrane potential. We also observed that subjecting mice to an HFD did not alter mitochondrial bioenergetics. This could be due to subjecting our mice to a short-term high fat feeding regiment, which has previously been shown to have little impact on mitochondrial bioenergetics (19). We also observed that mitochondria from GRX2 heterozygotes contained higher PDH levels, which could also account for the increase in muscle fuel metabolism. PDH availability was also increased in WT mice fed an HFD; however, previous work has found that subjecting rodents to an HFD diminishes its activity (36). Together, manipulation of S-glutathionylation pathways in muscle mitochondria augments fuel combustion and respiration due to increased proton leaks and the maintenance of various proteins that are critical for nutrient oxidation and metabolism in a deglutathionylated state.

Mitochondria are also quantifiably the most important ROS source in muscle cells (44). Production of $\mathrm{H}_{2} \mathrm{O}_{2}$ relies on the same fuel-oxidizing and electron-transferring pathways that make ATP. $\mathrm{H}_{2} \mathrm{O}_{2}$ was considered for a long time to be a noxious agent that induces oxidative distress. However, it is now clear that $\mathrm{H}_{2} \mathrm{O}_{2}$, when maintained at low levels, serves as a second messenger for normal muscle physiology. Similar to any other second messenger, $\mathrm{H}_{2} \mathrm{O}_{2}$ levels are regulated through its production and degradation.. In this study, we have shown that mitochondria from $\mathrm{GRX}^{+/-}$mice fed an HFD generated more $\mathrm{H}_{2} \mathrm{O}_{2}$ and the main sources of production were complexes I and II. This is attributed to the significant decrease in the overall S-glutathionylation of various proteins in muscle mitochondria. This observation is significant for several reasons. First, these findings are valuable from a "muscle regulation" point of view (17). $\mathrm{H}_{2} \mathrm{O}_{2}$ production in muscle is vital for adaptation to exercise, which includes bolstering antioxidant defenses and inducing mitochondrial biogenesis and myokine production (17). A recent study also found that mitochondrial $\mathrm{H}_{2} \mathrm{O}_{2}$ emissions were required to facilitate the repair of injured myofibers (13). In addition, it was also recently shown that protein $\mathrm{S}$ glutathionylation reactions are integral for modulating $\mathrm{H}_{2} \mathrm{O}_{2}$ signals for the control of energy metabolism and myofiber contraction during fatiguing exercise (16) and that provision of the fidelity of mitochondrial redox signaling prevents sarcopenia and improves exercise tolerance in aged mice (6). Our findings complement these other studies by demonstrating that manipulating mitochondrial redox signals can increase $\mathrm{H}_{2} \mathrm{O}_{2}$ production while also augmenting fuel metabolism. It is also critical to point out that in this study it was found that mice heterozygous for GRX2 displayed a higher capacity for ROS handling. This included increased glutathione availability and greater protection from oxidative damage. This points to the possibility that manipulating mitochondrial redox signals might serve as an "exercise mimetic" by increasing ROS production for muscle adaptation. The second finding was that complexes I and II are the chief ROS sources. This is important for the following reasons: (i) Recent work has found that complex I is a major ROS source during intense exercise (45). In addition, complex II was also found to be a key ROS source in muscle (4). Further, ROS release from complex I has been suggested to play a part in the adaptation of muscle to exercise (30) and (ii) ROS pro- duction by complexes I and II is modulated by Sglutathionylation. Indeed, recent works have found that oxidation of glutathione pools results in the modification of complex I subunit NDUFS1, resulting in the inhibition of ROS production by muscle mitochondria (10). Similar observations have been made with cardiac tissue where modification of complex I with glutathione alters the rate of ROS production (15). Similarly, the S-glutathionylation of complex II also inhibits ROS production (8). Therefore, it is likely that deleting the Grx2 gene results in complex I and II deglutathionylation, increasing mitochondrial $\mathrm{H}_{2} \mathrm{O}_{2}$, a critical second messenger that regulates normal muscle physiology, growth, and metabolism.

One important feature of our findings as well is that mitochondrial ROS production increased despite the activation of proton leaks through UCP3 and ANT. This may seem counterintuitive given that the current dogma in regard to mitochondrial bioenergetics is that decreasing protonic back pressure on the respiratory chain diminishes ROS production by augmenting the successful transfer of electrons in the respiratory chain to complex IV for the reduction of $\mathrm{O}_{2}$ to $\mathrm{H}_{2} \mathrm{O}$. However, recent work has demonstrated that chronic activation of proton leaks and high rates of respiration can augment mitochondrial ROS production. For example, several studies have found that activation of UCP1 in brown fat can amplify mitochondrial $\mathrm{O}_{2}{ }^{--}$and $\mathrm{H}_{2} \mathrm{O}_{2}$ production by increasing fuel oxidation $(20,32,42)$. In addition, it was also found that activation of UCP3 in mice homozygous for GRX2 leads to an increase in mitochondrial ROS production (28). Overall, this does not preclude the importance of proton return for the limitation of mitochondrial ROS productionhowever; it does also indicate that prolonged induction of leaks may have the opposite effect, amplifying ROS production through increased fuel oxidation.

\section{Conclusions}

Here, we report for the first time that deleting the Grx2 gene can protect mice from diet-induced weight gain. This protective effect was related to increased muscle fuel metabolism that was related to an augmentation of mitochondrial proton leaks and respiration. We also attribute this effect to an increase in mitochondrial $\mathrm{H}_{2} \mathrm{O}_{2}$ formation, which serves as a critical second messenger for normal muscle physiology. Although we observed that this protective effect is related to increased muscle mitochondrial metabolism, it is likely that other factors external to muscle can also play a significant role in facilitating increased energy expenditure and fuel metabolism. Therefore, more work is required to evaluate the relationship between this protective phenotype and changes in the GRX2 glutathionylome. Future considerations to push these concepts forward include generating a muscle-specific GRX2 knock-out model, which could serve as a valuable tool in evaluating these phenomena. This would also include potential studies on human populations and an in-depth analysis on the impact of exercise, weight gain, and obesity on mitochondrial bioenergetics and the glutathionylome in muscles. It is anticipated that the full delineation of the mechanisms responsible for this protective effect will lead to the development of novel pharmaceuticals that target these pathways for the prevention/reversal of obesity. 


\section{Experimental}

\section{Chemicals}

Acrylamide solution, Laemmli buffer, tetramethylethylenediamine, and nitrocellulose membrane were obtained from Bio-Rad. Goat anti-mouse antibody, oxidative phosphorylation (OXPHOS) primary antibody cocktail, PDH primary antibody cocktail, and UCP3 primary antibody were obtained from Abcam. The triglyceride assay kit and insulin ELISA kit were obtained from Cederlane and Millipore, respectively. Amplex UltraRed (AUR) reagent and $100 \mathrm{bp}$ protein ladder were obtained from Invitrogen. Atpenin A5, goat anti-rabbit antibody, NDUSF1 primary antibody, and superoxide dismutase (SOD)2 primary antibody were obtained from Santa Cruz. Adenosine diphosphate (ADP), antimycin A, bovine serum albumin (BSA), disulfiram, ethylene glycolbis ( $\beta$-aminoethyl ether)-N,N, $\mathrm{N}^{\prime}, \mathrm{N}^{\prime}$-tetraacetic acid (EGTA), GDP, genapin, glutathione assay kit, glycine, HEPES, horseradish peroxidase (HRP), $\mathrm{KMV}$, malic acid, mannitol, $\mathrm{MgCl}_{2}$, $\mathrm{NaCl}$, NADH, oligomycin, palmitoyl carnitine, ponceau, pyruvic acid, the red Extract-N-Amp PCR kit, rotenone, SOD, sodium azide, subtilisin A, succinic acid, and sucrose were all obtained from Sigma.

\section{Animals and diet}

Animals were cared for in accordance with the principles and guidelines of the Canadian Council on Animal Care and the Institute of Laboratory Animal Resources (National Research Council). All procedures using mice were approved by the Animal Care and Use Committee at Memorial University of Newfoundland. Male and female mice heterozygous for GRX2 were paired for breeding and housed at $25^{\circ} \mathrm{C}$ on a $12-\mathrm{h}$ day/night light cycle and provided free access to water and chow (Teklad Global 18\% Protein Rodent Diet, 2018). Litters were weaned at 3 weeks of age and ear notched to determine genotype. Male GRX2 $2^{+-}$mice and WT littermates were fed either an HFD (Teklad diet TD.06415) or matched CD (Teklad TD.06416) ad libitum. Mouse mass and food consumption were measured weekly. Blood glucose levels were also measured weekly by using a glucometer. At 10 weeks of age, mice were euthanized by cervical dislocation under heavy anesthesia (5\% isoflurane) and blood was collected by cardiac puncture. Liver, kidney, heart, skeletal muscle (pooled forelimb, hindlimb, and pectoral muscles), and abdominal fat (posterior subcutaneous depots) were collected, dried, and weighed. Livers were then sectioned and used for histological staining. Gastrocnemius muscle was also used for histological staining and the remaining muscle was used for the isolation of mitochondria. H\&E, Oil Red-O, and PAS staining of liver sections and gastrocnemius muscle were performed by the histology unit of the Medical Education and Laboratory Support Services at the Memorial University of Newfoundland Faculty of Medicine. PAS staining of glycogen granules was confirmed by incubating sections in amylase.

\section{Genotyping}

Genotyping was carried out by using the Extract-N-Amp Tissue PCR kit according to the manufacturer's instructions. PCR procedures utilized $1 \mu \mathrm{L}$ of $0.5 \mu M$ Grx 2 forward primer, $1 \mu \mathrm{L}$ of $0.5 \mu M$ Grx 2 reverse primer, $1 \mu \mathrm{L}$ of $0.5 \mu M$ Grx2 neo primer (see below), $4 \mu \mathrm{L}$ of DNA solution, $3 \mu \mathrm{L}$ nuclease-free water, and $10 \mu \mathrm{L}$ of REDExtract-N-Amp Tissue PCR Kit Reaction Mixture, giving a final volume of $20 \mu \mathrm{L}$. Primer sequences for the Grx2 gene were produced by Integrated DNA technologies (Forward: 5'-GAC CTA GCC TAC CAG ACT TGG CTG AAA TTT ATT C- $3^{\prime}$ [located in intron 2] Reverse: $5^{\prime}$-CAT AGA CAC TCT TCA CTT TCA AGC CCA CCC TC-3' and Neo: 5'-CCT ACA TTT TGA ATG GAA GGA TTG GAG CTA CGG G-3') (7). PCR samples were electrophoresed in a $1.5 \%(\mathrm{w} / \mathrm{v})$ agarose gel supplemented with $5 \mu \mathrm{L}$ SYBR safe. Fragment size estimation was performed using the Trackit $100 \mathrm{bp}$ DNA ladder. Gene amplification was imaged using the Alpha Innotech ChemiImager Ready System. WT mice produced a single 729 bp-long nucleotide sequence. GRX2-/- mice produced a bp fragment that was $510 \mathrm{bp}$ in size, and $\mathrm{GRX}^{+/-}$mice contained both nucleotide sequence fragments (Fig. 2A).

\section{Blood serum analysis}

Blood samples were centrifugated at $2000 \mathrm{~g}$ for $5 \mathrm{~min}$ to collect blood serum stored at $-80^{\circ} \mathrm{C}$ for further analysis. Serum insulin (EMD Millipore), triglycerides (Wako), and glutathione (Sigma) levels were measured according to the manufacturer's instructions.

\section{Mitochondrial preparation}

All steps were performed on ice or at $4^{\circ} \mathrm{C}$. Fore and hindlimb and pectoral muscles were pooled and placed in basic medium (BM; KCl; $140 \mathrm{~m} M$, HEPES; $20 \mathrm{~m} M$, EGTA; $1 \mathrm{~m} M$, and $\mathrm{MgCl}_{2} ; 5 \mathrm{~m} M, \mathrm{pH} 7.0$ with $\left.6 \mathrm{~N} \mathrm{HCl}\right)$. Skeletal muscle was cleaned of fat and connective tissue, weighed, and minced on a teflon watch glass. Minced tissue was then placed in $15 \mathrm{~mL}$ of homogenization medium (BM containing ATP; $1 \mathrm{~m} M, 1 \%$ (w/v) BSA and $1 \mathrm{U}$ subtilisin A). Samples were homogenized by using the Potter-Elvejham method and a variable speed reversible homogenizer (Glas-Col). The homogenate was centrifuged at $800 \mathrm{~g}$ for $9 \mathrm{~min}$. The supernatant was transferred to a second tube and centrifuged at $10,000 \mathrm{~g}$ for $9 \mathrm{~min}$. The supernatant was discarded, and the sides of the tube were carefully wiped to remove any excess fat. The pellet was resuspended in $1 \mathrm{~mL}$ of $\mathrm{BM}$ and incubated for $5 \mathrm{~min}$ at $4^{\circ} \mathrm{C}$ to promote myofiber repolymerization. Twenty five milliliters of BM was then added to each tube, and samples were centrifuged at $800 \mathrm{~g}$ to remove the myofibers. The supernatant was then collected and centrifuged at $10,000 \mathrm{~g}$ for $9 \mathrm{~min}$ to pellet skeletal muscle mitochondria. The mitochondrial pellet was resuspended in $\sim 200 \mu \mathrm{L}$ to give a final protein concentration equivalent to mitochondria of $\sim 10 \mathrm{mg} / \mathrm{mL}$. Protein concentration was determined with the Bradford Assay.

\section{Estimation of mitochondrial PSSG levels}

Overall, the number of PSSG adducts was measured as previously described, with a few alterations (2). Briefly, muscle tissues were extracted immediately and placed in icecold BM containing $25 \mathrm{mM}$ N-ethylmaleimide (NEM) to irreversibly alkylate free protein cysteine thiols and prevent auto-glutathionylation due to exposure of samples to ambient oxygen. Mitochondria were then isolated as described earlier using BM and homogenizing medium containing $25 \mathrm{mM}$ NEM. Next, mitochondria were diluted to a final concentration 
of $2 \mathrm{mg} / \mathrm{mL}$, washed twice with BM to remove any excess NEM, and incubated in buffer containing $2 \mathrm{~m} M$ DTT to reduce PSSG adducts. Mitochondria were then washed thrice in BM and incubated for $30 \mathrm{~min}$ at $25^{\circ} \mathrm{C}$ in RIPA buffer containing $100 \mu M$ 5,5'-dithiobis(2-nitrobenzoic acid). Spectrophotometric changes were measured at $A_{412}$ using a SpectraMax M5 plate reader, corrected for background, and then PSSG adduct concentration was calculated $\left(\varepsilon_{412}=13,600 \mathrm{~m}^{-1} \mathrm{~cm}^{-1}\right)$. Values were corrected for background absorbance.

\section{Measurement of GRX1 and GRX2 activities}

To measure GRX1 and GRX2 accurately, mitochondrial compartments were isolated as described in Mailloux and Harper (23). Muscle mitochondria were isolated as described earlier, diluted to $2 \mathrm{mg} / \mathrm{mL}$ in BM containing $1 \%$ (v/v) digitonin, and finally incubated on ice for $30 \mathrm{~min}$. Samples were then centrifuged at $11,000 \mathrm{~g}$ for $10 \mathrm{~min}$. The resulting supernatant, which contains outer mitochondrial membrane fragments and the intermembrane space, was collected and placed on ice. The mitoplast pellet (matrix + the inner mitochondrial membrane) was washed twice in BM and resuspended in buffer containing $0.1 \%$ (v/v) Triton X-100 to permeabilize the inner membrane (37). GRX1 and 2 activities were measured using the hydroxyethyldisulfide (HEDS) assay (21). Briefly, in the wells of a microplate, HEDS $(1.8 \mathrm{mM})$ was incubated with $\mathrm{GSH}(0.9 \mathrm{mM})$ for $30 \mathrm{~min}$ at $25^{\circ} \mathrm{C}$ to generate a hydroxyethyl-glutathione disulfide adduct. The wells were then supplemented with glutathione reductase $(0.4 \mathrm{U} / \mathrm{mL})$, and the solution was allowed to equilibrate for 5 min. Reactions were then initiated by the addition of $20 \mu \mathrm{L}$ of supernatant or dissolved mitoplasts, NADPH (1 mM), and GSH $(1 \mathrm{~m} M)$. The consumption of NADPH was monitored spectrophotometrically at $A_{340}$ over $5 \mathrm{~min}$ at $30 \mathrm{~s}$ intervals by using SpectraMax M5 plate reader. Raw values were then corrected to background, and the rate of GRX1 and GRX2 activity was calculated $\left(\varepsilon_{340}=6220 \mathrm{~m}^{-1} \mathrm{~cm}^{-1}\right)$.

\section{Estimation of $\mathrm{H}_{2} \mathrm{O}_{2}$ production}

The AUR assay was utilized to measure the rate of $\mathrm{H}_{2} \mathrm{O}_{2}$ production and determine which ROS-generating enzymes served as high-capacity sites of production. Skeletal muscle mitochondria were diluted to $1.5 \mathrm{mg} / \mathrm{mL}$ in ice-cold $\mathrm{BM}$ and stored on ice before commencing assays. Samples were then diluted to $0.15 \mathrm{mg} / \mathrm{mL}$ in the individual wells of black clearbottom 96-well plates containing BM. Wells were then supplemented with HRP (3 U/mL), SOD1 (25 U/mL), and AUR $(10 \mu M)$. Reactions were then initiated by adding substrate; pyruvate $(50 \mu M)$, malate $(50 \mu M)$, succinate $(50 \mu M)$, or palmitoyl-carnitine $(20 \mu M)$. Note that for experiments using palmitoyl-carnitine, mitochondria were preincubated for $5 \mathrm{~min}$ at $25^{\circ} \mathrm{C}$ in carnitine $(2 \mathrm{mM})$ before adding AUR reagents. The final volume for all reactions in each well was $200 \mu \mathrm{L}$. To determine which site was responsible for generating ROS in our model systems, mitochondria were incubated in a variety of inhibitors before the addition of AUR reagents and commencing the assays (Fig. 9). To assess the ROS source(s) in mitochondria energized with pyruvate and malate, samples were incubated at $25^{\circ} \mathrm{C}$ for $5 \mathrm{~min}$ with the following site-specific ROS production inhibitors: KMV (10 $\mathrm{m} M$; KGDH inhibitor), atpenin A5 (50 $\mu M$; complex II inhibitor), or myxothiazol (4 $\mu M$; complex III inhibitor). For samples energized with succinate or palmitoyl-carnitine/ carnitine, mitochondria were treated with rotenone $(4 \mu M$; complex I inhibitor), atpenin A5 $(50 \mu M)$, or myxothiazol $(4 \mu M)$. Changes in resorufin fluorescence were followed at excitation/ emission wavelengths $(565 \mathrm{~nm} / 600 \mathrm{~nm})$ for $5 \mathrm{~min}$, with reads taken once every $30 \mathrm{~s}$ by using a SpectraMax M5 plate reader. Values were normalized to background fluorescence.

\section{Polarographic measurements of oxygen consumption}

Mitochondrial oxygen consumption was evaluated by using a Hansatech Oxytherm electrode. Skeletal muscle mitochondria were diluted to $0.2 \mathrm{mg} / \mathrm{mL}$ in the reaction chamber containing respiration buffer (mannitol; $220 \mathrm{mM}$, sucrose; $70 \mathrm{~m} M$, EGTA; $1 \mathrm{~m} M$, HEPES; $20 \mathrm{~m} M, 0.5 \%$ w/v BSA, $\mathrm{KH}_{2} \mathrm{PO}_{4} ; 10 \mathrm{~m} M$, and $\mathrm{MgCl}_{2} ; 2 \mathrm{~m} M, \mathrm{pH}$ 7.4). Once a baseline oxygen consumption was established, pyruvate $(10 \mathrm{~m} M)$, malate $(2 \mathrm{~m} M)$, succinate $(5 \mathrm{mM})$, or palmitoyl-carnitine $(50 \mu M)$ and carnitine $(2 \mathrm{mM}$; added $5 \mathrm{~min}$ before palmitoylcarnitine) were added to the chamber to initiate and record state 2 respiration. State 3 respiration was then stimulated by injecting ADP $(1 \mathrm{mM})$ into the reaction chamber. Oligomycin $(4 \mu \mathrm{g} / \mathrm{mL})$, an inhibitor of ATP synthase, was then added to induce state 4 respiration (proton leak-dependent respiration). Finally, the reaction was ended with the addition of antimycin $\mathrm{A}(4 \mu M)$. Rates of $\mathrm{O}_{2}$ consumption under the different states of respiration were normalized to the rate of consumption after the addition of antimycin A.

\section{Investigation of proton leak-dependent respiration}

Skeletal muscle mitochondria were diluted to $0.2 \mathrm{mg} / \mathrm{mL}$ in the reaction chamber containing respiration buffer. Once a baseline for oxygen consumption was established, oligomycin $(4 \mathrm{mg} / \mathrm{mL})$ was added and mitochondria were allowed to incubate for a few moments. Pyruvate $(10 \mathrm{~m} M)$ and malate $(2 \mathrm{mM})$ were then added; proton leak-dependent respiration was recorded. Known inhibitors for UCP3 (GDP; $1 \mathrm{~m} M$ or genipin; $50 \mu M$ ) and ANT (octanoyl-carnitine; $150 \mu M$ ) were then added to the chamber, and respiration was measured.

To determine whether proton leaks could be inhibited by S-glutathionylation, mitochondria were incubated in disulfiram. Mitochondria were prepared at $0.2 \mathrm{mg} / \mathrm{mL}$ in reaction buffer as previously discussed and incubated in the presence or absence of disulfiram $(500 \mu M)$ for $15 \mathrm{~min}$. Once again, proton leak was induced with the addition of oligomycin $(4 \mathrm{mg} / \mathrm{mL})$ followed by pyruvate and malate $(10$ and $2 \mathrm{mM})$. The impact of disulfiram on proton leak-dependent respiration was then assessed.

\section{Immunoblot analysis}

Isolated mitochondria were diluted to $3 \mathrm{mg} / \mathrm{mL}$ in $50 \mu \mathrm{L}$ RIPA and $50 \mu \mathrm{L}$ of Lammli buffer (BioRad). The samples are then incubated at $100^{\circ} \mathrm{C}$ for $10 \mathrm{~min}$. Sixty micrograms of protein was loaded into each well of a $10 \%$ isocratic sodium dodecyl sulfate gel. For detection of UCP3, $100 \mu \mathrm{g}$ of protein was loaded. Electrophoresis was conducted at $80 \mathrm{~V}$ until the proteins had passed through the stacking gel followed by a 40 -min run at $200 \mathrm{~V}$ with the Mini-protean Tetra System (Bio-Rad). Protein was then transferred to nitrocellulose membrane for $1 \mathrm{~h}$ at $120 \mathrm{~V}$ by tank transfer. The successful transfer of proteins to the nitrocellulose membrane was 
determined using Ponceau S. Membranes were rinsed with Tris-buffered saline (TBS) containing $0.1 \% \mathrm{v} / \mathrm{v}$ Tween-20 (TBS-T) and then incubated for $1 \mathrm{~h}$ at room temperature in blocking solution (TBS-T and 5\% (w/v) nonfat skim milk). Blocking solution was removed with 2 washes of TBS-T followed by overnight incubation in primary antibody (antiKGDH [1/3000], anti-PDH antibody cocktail [1/3000], OXPHOS antibody cocktail [1/3000], anti-UCP3 antibody cocktail [1/1000], or loading controls anti-NDUSF1 antibody cocktail [1/3000], or anti-SOD2 [1/2000]) diluted in TBS-T containing $5 \% \mathrm{w} / \mathrm{v} \mathrm{BSA}+2 \% \mathrm{w} / \mathrm{v} \mathrm{NaN} \mathrm{N}_{3}$ at $4^{\circ} \mathrm{C}$ with moderate agitation. Membranes were washed twice with TBS-T and probed with secondary antibody (goat anti-rabbit or goat antimouse secondary antibodies) diluted in blocking solution. Bands were visualized by using WestPico Super Signal Chemiluminescent substrate and ImageQuant LAS 4000. Band intensities were quantified by using ImageJ software.

\section{Data analysis}

Graph pad prism 6 software was utilized for all statistical analysis. All data are represented as the mean \pm standard error of mean with $N \geq 4$. Two-way analysis of variance with a Tukey's post hoc test was employed for all experimental results with the exception of proton leak investigations, which utilized Fisher's least significance difference. Statistical significance was represented as follows: * or \#; $p \leq 0.05, * *$ or \#\#; $p \leq 0.01$, *** or \#\#\#; $p \leq 0.001$, **** or \#\#\#\#; $p \leq 0.0001$.

\section{Authors' Contributions}

A.Y. co-designed and conducted all experiments, ran data analysis, and co-wrote the article. D.G. co-ran experiments and helped conduct data analysis for Figures 2, 3, and 4. N.K. and R.G. co-ran experiments and aided with the design of experiments for Figures 5, 7, 8, and 9. M.O. co-designed and co-ran experiments in Figure 4. R.J.M. designed all experiments, conducted data analysis, co-wrote the article, and acquired funding for the study.

\section{Acknowledgments}

This work was supported by grants provided by the Natural Sciences and Engineering Research Council (NSERC) of Canada. R.G. was financially supported by a University Student Summer Internship Program (USSIP) award provided by Memorial University of Newfoundland.

\section{Author Disclosure Statement}

No competing financial interests exist.

\section{Supplementary Material}

Supplementary Figure S1

Supplementary Figure S2

Supplementary Figure S3

Supplementary Figure S4

\section{References}

1. Aguer C, Fiehn O, Seifert EL, Bezaire V, Meissen JK, Daniels A, Scott K, Renaud JM, Padilla M, Bickel DR, Dysart M, Adams SH, and Harper ME. Muscle uncoupling protein 3 overexpression mimics endurance training and reduces circulating biomarkers of incomplete beta-oxidation. FASEB J 27: 4213-4225, 2013.

2. Beer SM, Taylor ER, Brown SE, Dahm CC, Costa NJ, Runswick MJ, and Murphy MP. Glutaredoxin 2 catalyzes the reversible oxidation and glutathionylation of mitochondrial membrane thiol proteins: implications for mitochondrial redox regulation and antioxidant DEFENSE. J Biol Chem 279: 47939-47951, 2004.

3. Bell FP. Inhibition of adenine nucleotide translocase by oleoylcarnitine, oleoylcoa and oleate in isolated arterial mitochondria. Atherosclerosis 37: 21-32, 1980.

4. Brand MD. Mitochondrial generation of superoxide and hydrogen peroxide as the source of mitochondrial redox signaling. Free Radic Biol Med 100: 14-31, 2016.

5. Brand MD and Esteves TC. Physiological functions of the mitochondrial uncoupling proteins UCP2 and UCP3. Cell Metab 2: 85-93, 2005.

6. Campbell MD, Duan J, Samuelson AT, Gaffrey MJ, Merrihew GE, Egertson JD, Wang L, Bammler TK, Moore RJ, White CC, Kavanagh TJ, Voss JG, Szeto HH, Rabinovitch PS, MacCoss MJ, Qian WJ, and Marcinek DJ. Improving mitochondrial function with SS-31 reverses age-related redox stress and improves exercise tolerance in aged mice. Free Radic Biol Med 134: 268-281, 2018.

7. Chalker J, Gardiner D, Kuksal N, and Mailloux RJ. Characterization of the impact of glutaredoxin-2 (GRX2) deficiency on superoxide/hydrogen peroxide release from cardiac and liver mitochondria. Redox Biol 15: 216-227, 2018.

8. Chen YR, Chen CL, Pfeiffer DR, and Zweier JL. Mitochondrial complex II in the post-ischemic heart: oxidative injury and the role of protein S-glutathionylation. $J$ Biol Chem 282: 32640-32654, 2007.

9. Chouchani ET, Kazak L, Jedrychowski MP, Lu GZ, Erickson BK, Szpyt J, Pierce KA, Laznik-Bogoslavski D, Vetrivelan R, Clish CB, Robinson AJ, Gygi SP, and Spiegelman BM. Mitochondrial ROS regulate thermogenic energy expenditure and sulfenylation of UCP1. Nature 532: 112-116, 2016.

10. Gill RM, O'Brien M, Young A, Gardiner D, and Mailloux RJ. Protein S-glutathionylation lowers superoxide/hydrogen peroxide release from skeletal muscle mitochondria through modification of complex I and inhibition of pyruvate uptake. PLoS One 13: e0192801, 2018.

11. Harper ME, Green K, and Brand MD. The efficiency of cellular energy transduction and its implications for obesity. Annu Rev Nutr 28: 13-33, 2008.

12. Heo JW, No MH, Park DH, Kang JH, Seo DY, Han J, Neufer PD, and Kwak HB. Effects of exercise on obesityinduced mitochondrial dysfunction in skeletal muscle. Korean J Physiol Pharmacol 21: 567-577, 2017.

13. Horn A, Van der Meulen JH, Defour A, Hogarth M, Sreetama SC, Reed A, Scheffer L, Chandel NS, and Jaiswal JK. Mitochondrial redox signaling enables repair of injured skeletal muscle cells. Sci Signal 10: pii:eaaj1978, 2017.

14. Hurd TR, Costa NJ, Dahm CC, Beer SM, Brown SE, Filipovska A, and Murphy MP. Glutathionylation of mitochondrial proteins. Antioxid Redox Signal 7: 999-1010, 2005.

15. Hurd TR, Requejo R, Filipovska A, Brown S, Prime TA, Robinson AJ, Fearnley IM, and Murphy MP. Complex I within oxidatively stressed bovine heart mitochondria is glutathionylated on Cys-531 and Cys-704 of the 75-kDa subunit: potential role of CYS residues in decreasing oxidative damage. J Biol Chem 283: 24801-24815, 2008. 
16. Kramer PA, Duan J, Gaffrey MJ, Shukla AK, Wang L, Bammler TK, Qian WJ, and Marcinek DJ. Fatiguing contractions increase protein S-glutathionylation occupancy in mouse skeletal muscle. Redox Biol 17: 367-376, 2018.

17. Kramer PA, Duan J, Qian WJ, and Marcinek DJ. The measurement of reversible redox dependent post-translational modifications and their regulation of mitochondrial and skeletal muscle function. Front Physiol 6: 347, 2015.

18. Kuksal N, Chalker J, and Mailloux RJ. Progress in understanding the molecular oxygen paradox-function of mitochondrial reactive oxygen species in cell signaling. Biol Chem 398: 1209-1227, 2017.

19. Leduc-Gaudet JP, Reynaud O, Chabot F, Mercier J, Andrich DE, St-Pierre DH, and Gouspillou G. The impact of a short-term high-fat diet on mitochondrial respiration, reactive oxygen species production, and dynamics in oxidative and glycolytic skeletal muscles of young rats. Physiol Rep 6 [Epub ahead of print]; DOI: 10.14814/phy2.13548, 2018.

20. Mailloux RJ, Adjeitey CN, Xuan JY, and Harper ME. Crucial yet divergent roles of mitochondrial redox state in skeletal muscle vs. brown adipose tissue energetics. FASEB J 26: 363-375, 2012.

21. Mailloux RJ, Craig Ayre D, and Christian SL. Induction of mitochondrial reactive oxygen species production by GSH mediated S-glutathionylation of 2-oxoglutarate dehydrogenase. Redox Biol 8: 285-297, 2016.

22. Mailloux RJ, Fu A, Robson-Doucette C, Allister EM, Wheeler MB, Screaton R, and Harper ME. Glutathionylation state of uncoupling protein-2 and the control of glucosestimulated insulin secretion. J Biol Chem 287: 39673-39685, 2012.

23. Mailloux RJ and Harper ME. Glucose regulates enzymatic sources of mitochondrial NADPH in skeletal muscle cells; a novel role for glucose-6-phosphate dehydrogenase. FASEB J 24: 2495-2506, 2010.

24. Mailloux RJ, McBride SL, and Harper ME. Unearthing the secrets of mitochondrial ROS and glutathione in bioenergetics. Trends Biochem Sci 38: 592-602, 2013.

25. Mailloux RJ, Seifert EL, Bouillaud F, Aguer C, Collins S, and Harper ME. Glutathionylation acts as a control switch for uncoupling proteins UCP2 and UCP3. J Biol Chem 286: 21865-21875, 2011.

26. Mailloux RJ and Treberg JR. Protein S-glutathionlyation links energy metabolism to redox signaling in mitochondria. Redox Biol 8: 110-118, 2016.

27. Mailloux RJ and Willmore WG. S-glutathionylation reactions in mitochondrial function and disease. Front Cell Dev Biol 2: 68, 2014.

28. Mailloux RJ, Xuan JY, Beauchamp B, Jui L, Lou M, and Harper ME. Glutaredoxin-2 is required to control proton leak through uncoupling protein-3. J Biol Chem 288: 83658379, 2013.

29. Mailloux RJ, Xuan JY, McBride S, Maharsy W, Thorn S, Holterman CE, Kennedy CR, Rippstein P, deKemp R, da Silva J, Nemer M, Lou M, and Harper ME. Glutaredoxin-2 is required to control oxidative phosphorylation in cardiac muscle by mediating deglutathionylation reactions. $J$ Biol Chem 289: 14812-14828, 2014.

30. Mason S and Wadley GD. Skeletal muscle reactive oxygen species: a target of good cop/bad cop for exercise and disease. Redox Rep 19: 97-106, 2014.
31. McGarry DJ, Chen W, Chakravarty P, Lamont DL, Wolf CR, and Henderson CJ. Proteome-wide identification and quantification of S-glutathionylation targets in mouse liver. Biochem J 469: 25-32, 2015.

32. Mills EL, Pierce KA, Jedrychowski MP, Garrity R, Winther S, Vidoni S, Yoneshiro T, Spinelli JB, Lu GZ, Kazak L, Banks AS, Haigis MC, Kajimura S, Murphy MP, Gygi SP, Clish CB, and Chouchani ET. Accumulation of succinate controls activation of adipose tissue thermogenesis. Nature 560: 102-106, 2018.

33. Muoio DM. Metabolic inflexibility: when mitochondrial indecision leads to metabolic gridlock. Cell 159: 12531262, 2014.

34. Murphy MP. Mitochondrial thiols in antioxidant protection and redox signaling: distinct roles for glutathionylation and other thiol modifications. Antioxid Redox Signal 16: 476495, 2012.

35. O'Brien M, Chalker J, Slade L, Gardiner D, and Mailloux RJ. Protein S-glutathionylation alters superoxide/hydrogen peroxide emission from pyruvate dehydrogenase complex. Free Radic Biol Med 106: 302-314, 2017.

36. Odland LM, Heigenhauser GJ, and Spriet LL. Effects of high fat provision on muscle PDH activation and malonylCoA content in moderate exercise. J Appl Physiol (1985) 89: 2352-2358, 2000.

37. Oldford C, Kuksal N, Gill R, Young A, and Mailloux RJ. Estimation of the hydrogen peroxide producing capacities of liver and cardiac mitochondria isolated from C57BL/6N and C57BL/6J mice. Free Radic Biol Med 135: 15-27, 2019.

38. Pastore A and Piemonte F. Protein glutathionylation in cardiovascular diseases. Int J Mol Sci 14: 20845-20876, 2013.

39. Podrini C, Borghesan M, Greco A, Pazienza V, Mazzoccoli $\mathrm{G}$, and Vinciguerra M. Redox homeostasis and epigenetics in non-alcoholic fatty liver disease (NAFLD). Curr Pharm Des 19: 2737-2746, 2013.

40. Podrini C, Cambridge EL, Lelliott CJ, Carragher DM, Estabel J, Gerdin AK, Karp NA, Scudamore CL, Sanger Mouse Genetics P, Ramirez-Solis R, and White JK. Highfat feeding rapidly induces obesity and lipid derangements in C57BL/6N mice. Mamm Genome 24: 240-251, 2013.

41. Queiroga CS, Almeida AS, Martel C, Brenner C, Alves $\mathrm{PM}$, and Vieira HL. Glutathionylation of adenine nucleotide translocase induced by carbon monoxide prevents mitochondrial membrane permeabilization and apoptosis. J Biol Chem 285: 17077-17088, 2010.

42. Shabalina IG, Vrbacky M, Pecinova A, Kalinovich AV, Drahota Z, Houstek J, Mracek T, Cannon B, and Nedergaard J. ROS production in brown adipose tissue mitochondria: the question of UCP1-dependence. Biochim Biophys Acta 1837: 2017-2030, 2014.

43. Shelton MD, Chock PB, and Mieyal JJ. Glutaredoxin: role in reversible protein s-glutathionylation and regulation of redox signal transduction and protein translocation. Antioxid Redox Signal 7: 348-366, 2005.

44. Wong HS, Benoit B, and Brand MD. Mitochondrial and cytosolic sources of hydrogen peroxide in resting $\mathrm{C} 2 \mathrm{C} 12$ myoblasts. Free Radic Biol Med 130: 140-150, 2018.

45. Wong HS, Dighe PA, Mezera V, Monternier PA, and Brand MD. Production of superoxide and hydrogen peroxide from specific mitochondrial sites under different bioenergetic conditions. J Biol Chem 292: 16804-16809, 2017. 
46. Wu H, Yu Y, David L, Ho YS, and Lou MF. Glutaredoxin 2 (Grx2) gene deletion induces early onset of age-dependent cataracts in mice. J Biol Chem 289: 36125-36139, 2014.

47. Xu K, Morgan KT, Todd Gehris A, Elston TC, and Gomez SM. A whole-body model for glycogen regulation reveals a critical role for substrate cycling in maintaining blood glucose homeostasis. PLoS Comput Biol 7: e1002272, 2011.

48. Ye ZW, Zhang J, Ancrum T, Manevich Y, Townsend DM, and Tew KD. Glutathione S-transferase P-mediated protein S-glutathionylation of resident endoplasmic reticulum proteins influences sensitivity to drug-induced unfolded protein response. Antioxid Redox Signal 26: 247-261, 2017.

49. Young A, Gill R, and Mailloux RJ. Protein S-glutathionylation: the linchpin for the transmission of regulatory information on redox buffering capacity in mitochondria. Chem Biol Interact 299: 151-162, 2019.

50. Zhang J, Ye ZW, Singh S, Townsend DM, and Tew KD. An evolving understanding of the S-glutathionylation cycle in pathways of redox regulation. Free Radic Biol Med 120: 204-216, 2018.

Address correspondence to:

Prof. Ryan J. Mailloux

Department of Biochemistry

Faculty of Science

Memorial University of Newfoundland

St. John's, Newfoundland and Labrador A1B $3 \times 9$

Canada

E-mail: rjmailloux@mun.ca

Date of first submission to ARS Central, January 3, 2019; date of final revised submission, July 16, 2019; date of acceptance, July 17, 2019.

$\begin{aligned} & \text { Abbreviations Used } \\ \mathrm{ANOVA} & =\text { analysis of variance } \\ \mathrm{ANT} & =\text { adenine nucleotide translocase } \\ \mathrm{AUR} & =\text { Amplex UltraRed } \\ \mathrm{BM} & =\text { basic medium } \\ \mathrm{BSA} & =\text { bovine serum albumin } \\ \mathrm{CD} & =\text { control diet } \\ \mathrm{DIO} & =\text { diet-induced obesity } \\ \mathrm{DNP} & =\text { dinitrophenol } \\ \mathrm{DTT} & =\text { dithiothreitol } \\ \mathrm{FAD} & =\text { flavin adenine dinucleotide } \\ \mathrm{GDP} & =\text { guanosine diphosphate } \\ \mathrm{GRX} 2 & =\text { glutaredoxin-2 } \\ \mathrm{GSH} & =\text { reduced glutathione } \\ \mathrm{GST} & =\text { glutathione } S \text {-transferases } \\ \mathrm{H} \& \mathrm{E} & =\text { hematoxylin and eosin } \\ \mathrm{H}_{2} \mathrm{O}_{2} & =\text { hydrogen peroxide } \\ \mathrm{HEDS} & =\text { hydroxyethyldisulfide } \\ \mathrm{HFD} & =\text { high fat diet } \\ \mathrm{HRP} & =\text { horseradish peroxidase } \\ \mathrm{KGDH} & =\text { alpha-ketoglutarate dehydrogenase } \\ \mathrm{KMV} & =3 \text {-methyl-2-oxovaleric acid } \\ \mathrm{LSD} & =\text { least significance difference } \\ \mathrm{NEM} & =N \text {-ethylmaleimide } \\ \mathrm{O}_{2} & - \\ \mathrm{OXPHOS} & =\text { superoxide } \\ \mathrm{PAS} & =\text { oxidative periodic acid Schiff } \\ \mathrm{PDH} & =\text { pyruvate dehydrogenase } \\ \mathrm{PSSG} & =\text { protein-glutathione mixed disulfides } \\ \mathrm{ROS} & =\text { reactive oxygen species } \\ \mathrm{SEM} & =\text { standard error of the mean } \\ \mathrm{SOD} & =\text { superoxide dismutase } \\ \mathrm{TBS} & =\text { Tris-buffered saline } \\ \mathrm{UCP} & =\text { uncoupling protein } \\ \mathrm{WT} & =\text { wild-type } \\ & \end{aligned}$

